Review Article

\title{
Comparative Analysis of Protein Glycosylation Pathways in Humans and the Fungal Pathogen Candida albicans
}

\author{
Iván Martínez-Duncker, ${ }^{1}$ Diana F. Díaz-Jímenez, ${ }^{2}$ and Héctor M. Mora-Montes ${ }^{3}$ \\ ${ }^{1}$ Laboratorio de Glicobiología Humana, Facultad de Ciencias, Universidad Autónoma del Estado de Morelos, \\ Avenida Universidad 1001, Colonia Chamilpa, 62209 Cuernavaca, MOR, Mexico \\ ${ }^{2}$ Departamento de Ingeniería Genética, Centro de Investigaciones y Estudios Avanzados del IPN, 36821 Irapuato, GTO, Mexico \\ ${ }^{3}$ División de Ciencias Naturales y Exactas, Departamento de Biología, Campus Guanajuato, Universidad de Guanajuato, \\ Noria Alta s/n, Col. Noria Alta, 36050 Guanajuato, GTO, Mexico \\ Correspondence should be addressed to Héctor M. Mora-Montes; hmora@ugto.mx
}

Received 17 April 2014; Accepted 6 June 2014; Published 3 July 2014

Academic Editor: Todd R. Callaway

Copyright ( 2014 Iván Martínez-Duncker et al. This is an open access article distributed under the Creative Commons Attribution License, which permits unrestricted use, distribution, and reproduction in any medium, provided the original work is properly cited.

\begin{abstract}
Protein glycosylation pathways are present in all kingdoms of life and are metabolic pathways found in all the life kingdoms. Despite sharing commonalities in their synthesis, glycans attached to glycoproteins have species-specific structures generated by the presence of different sets of enzymes and acceptor substrates in each organism. In this review, we present a comparative analysis of the main glycosylation pathways shared by humans and the fungal pathogen Candida albicans: $N$-linked glycosylation, $\mathrm{O}$-linked mannosylation and glycosylphosphatidylinositol-anchorage. The knowledge of similarities and divergences between these metabolic pathways could help find new pharmacological targets for C. albicans infection.
\end{abstract}

\section{Introduction}

Although evolutionarily distant, humans and microorganisms of the Candida genus are closely related from a health perspective. C. albicans is a commensal organism that colonizes mucosal surfaces of the digestive tract and oral and vaginal cavities, and is able to cause superficial or systemic infections (candidiasis), particularly in the light of immunological host defects [1]. Nonetheless, other Candida species including C. glabrata, C. krusei, C. parapsilosis and C. tropicalis have also emerged as important causative agents of candidiasis. Intact glycosylation pathways in both, the human host and the fungal pathogen, are important, if not essential, for their development; thus, the knowledge of commonalities and divergences of these metabolic processes, as well as their functions, could help define pharmacological targets to suppress the pathogenicity of Candida and other fungal pathogens.

\section{The $\boldsymbol{N}$-Linked Glycosylation Pathway}

The $\mathrm{N}$-glycosylation pathway involves attachment of glycans to the amide nitrogen atom in the side chain of asparagine
(Asn) residues of eukaryotic, archaeal, and bacterial glycoproteins. The best described model where the eukaryotic $\mathrm{N}$ glycosylation pathway has been characterized in detail is the baker yeast Saccharomyces cerevisiae [2]. Through the years this model has helped to identify and characterize various human and fungal orthologs involved in this pathway.

The synthesis of the dolichol-linked glycan and its transfer to proteins are identical in both, human cells and $C$. albicans [3,4] (see Table 1 and Figure 1). In fact, these processes are quite conserved among eukaryotic cells and there are only a handful of organisms where these stages are slightly different, such as trypanosomatids, some protists, and the fungal pathogen Cryptococcus neoformans [5, 6].

The eukaryotic $N$-linked glycosylation pathway is divided in two sequential stages: (a) synthesis in the rough endoplasmic reticulum (rER) of the dolichol-linked glycan precursor Dol-PP-GlcNAc ${ }_{2} \mathrm{Man}_{9} \mathrm{Glc}_{3}$ and its transfer to a nascent protein and (b) the $N$-linked glycan processing and maturation in the rER and Golgi (Figure 1). Both stages require the action of different glycosyltransferases (GTs) and an adequate supply of donor substrates, which can be, depending on 


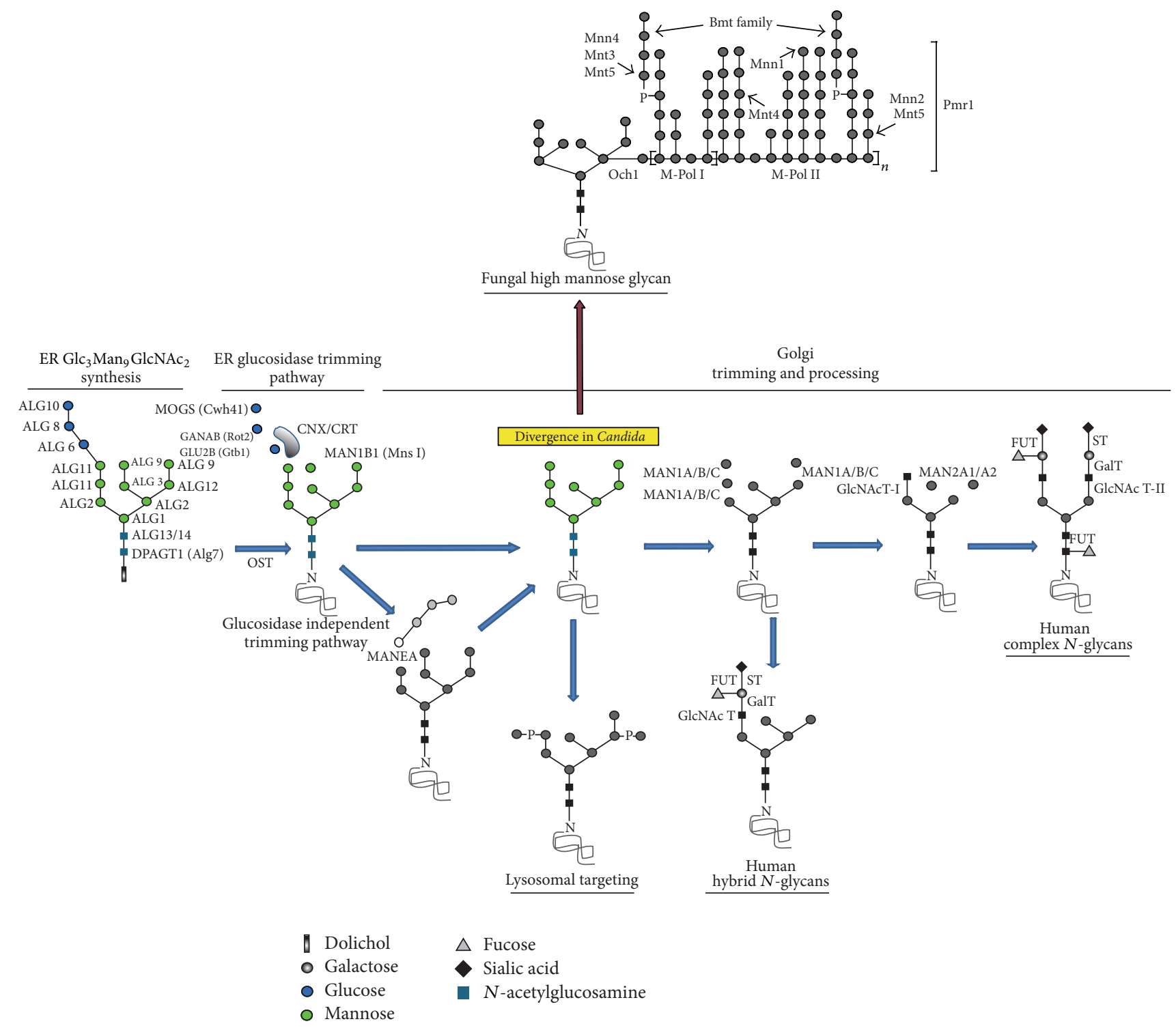

FIGURE 1: The $N$-glycosylation pathway. Commonalities and divergence in the $N$-linked glycosylation pathway. The shared structures between humans and Candida albicans have been colored, showing the rER synthesis of the $\mathrm{Glc}_{3} \mathrm{Man}_{9} \mathrm{GlcNAc}_{2}$ glycan and its transfer by the OST complex to a nascent protein. Once transferred, the $\mathrm{Glc}_{3} \mathrm{Man}_{9} \mathrm{GlcNAc}_{2}$ glycan is trimmed by the action of glucosidases and enters a quality control checkpoint performed by the CNX/CRT cycle. Once it passes this checkpoint, it is trimmed by mannosidase MAN1B1 to generate $\mathrm{Man}_{8} \mathrm{GlcNAc}_{2}$ structure. At this point divergence occurs with C. albicans that synthesizes high-mannose glycans. In humans, the $\mathrm{Man}_{8} \mathrm{GlcNAc}_{2}$ structure is further demannosylated to $\mathrm{Man}_{5}$ GlcNAc$_{2}$ by Golgi mannosidases type I (MAN1A, MAN1B, and MAN1C). This $\mathrm{N}$-linked glycan suffers further demannosylation and glycosylation processing by type II mannosidases (MAN2A1, MAN2A2), N-acetylgalactosaminyl transferases (GlcNAcT), galactosyltransferases (GalT), fucosyltransferases (FUT) and sialyltransferases (STs). In humans, a glucosidase-independent trimming of $\mathrm{Glc}_{3} \mathrm{Man}_{9} \mathrm{GlcNAc}_{2}$ takes place, generating a $\mathrm{Man}_{8} \mathrm{GlcNAc}_{2}$ structure. In addition, lysosomal targeting of glycoproteins through modification with phosphate groups is only found in human cells.

the GT family, nucleotide-activated sugars or dolicholactivated sugars.

The lipid dolichol used as a carrier in the first stage of $\mathrm{N}$-glycosylation is a polymer of isoprene units $\left(\mathrm{CH}_{3}-\right.$ $\left.\mathrm{C}\left(\mathrm{CH}_{3}\right)=\mathrm{CH}-\mathrm{CH}_{2}-\right)$ predominantly of $14-17$ units in the baker yeast [7], 19-22 in humans [8], and of undetermined length in Candida. Dolichol is modified in the rER cytosolic face by human and C. albicans orthologue GTs Alg7, Alg13/14,
Alg1, Alg2, and Alg11, using the nucleotide sugars UDPGlcNAc and GDP-Man as donor substrates to synthesize the Dol-PP-GlcNAc $\mathrm{Man}_{5}$ intermediate. This intermediate is then flipped from the cytosol to the rER lumen, where synthesis proceeds by GTs Alg3, Alg9, Alg12, Alg6, Alg8, and Alg10 that use the dolichol-linked sugars Dol-PP-Glc and Dol-PP-Man as donors to synthesize the glycan precursor Dol-PP-GlcNAc $\mathrm{Man}_{9} \mathrm{Glc}_{3}$. 
TABLE 1: Human and C. albicans homolog proteins involved in the $N$-linked glycosylation pathway.

\begin{tabular}{|c|c|c|c|c|c|}
\hline Protein function & Protein Human/Candida & Human ID* & Candida ID* & $\mathrm{Id}^{* *}$ & $\mathrm{COV}^{* * *}$ \\
\hline \multicolumn{6}{|l|}{ Glycosyltransferases } \\
\hline UDP-GlcNAc: Dol-P N-acetylglucosaminephosphotransferase & GT1/Alg7 & NP_001373.2 & XP_716028.1 & $37 \%$ & $87 \%$ \\
\hline $\begin{array}{l}\text { UDP-GlcNAc: Dol-PP-GlcNAc N-acetylglucosaminyl } \\
\text { transferase }\end{array}$ & Alg13 & NP_001093392.1 & XP_718987.1 & $30 \%$ & $60 \%$ \\
\hline $\begin{array}{l}\text { UDP-GlcNAc: Dol-PP-GlcNAc N-acetylglucosaminyl } \\
\text { transferase }\end{array}$ & Alg14 & NP_659425.1 & XP_717086.1 & $37 \%$ & $77 \%$ \\
\hline GPD-Man: Dol-PP-GlcNAc $2 \beta 1,4$-mannosyltransferase & Alg1 & NP_061982.3 & XP_711858.1 & $34 \%$ & $88 \%$ \\
\hline $\begin{array}{l}\text { GPD-Man: Dol-PP-GlcNAc }{ }_{2} \text { Man } \\
\alpha 1,3-\alpha 1,6 \text {-mannosyltransferase }\end{array}$ & Alg2 & NP_149078.1 & XP_710581.1 & $41 \%$ & $96 \%$ \\
\hline $\begin{array}{l}\text { GPD-Man: Dol-PP-GlcNAc } \operatorname{Man}_{3} \text { and } \\
\operatorname{Man}_{4} \alpha 1,2 \text {-mannosyltransferase }\end{array}$ & Alg11 & NP_001004127.2 & XP_712508.1 & $36 \%$ & $67 \%$ \\
\hline Dol-P-Man: Dol-PP-GlcNAc ${ }_{2} \mathrm{Man}_{5} \alpha 1,3$-mannosyltransferase & Alg3 & NP_001006942.1 & XP_712080.1 & $30 \%$ & $81 \%$ \\
\hline Dol-P-Man: Dol-PP-GlcNAc ${ }_{2} \mathrm{Man}_{7} \alpha 1,6$-mannosyltransferase & Alg12 & NP_077010.1 & XP_716986.1 & $33 \%$ & $86 \%$ \\
\hline $\begin{array}{l}\text { Dol-PP-Man: Dol-PP-GlcNAc }{ }_{2} \operatorname{Man}_{6} \text { and } \\
\text { Man8 } \alpha 1,3 \text {-mannosyltransferase }\end{array}$ & Alg9 & NP_001071158.1 & XP_713886.1 & $36 \%$ & $93 \%$ \\
\hline Dol-PP-Glc: Dol-PP-GlcNAc ${ }_{2} \operatorname{Man}_{9} \alpha 1,3$-glucosyltransferase & Alg6 & NP_037471.2 & XP_711029.1 & $37 \%$ & $87 \%$ \\
\hline Dol-PP-Glc: Dol-PP-GlcNAc ${ }_{2}$ Man $_{9}$ Glc $\alpha 1,3$-glucosyltransferase & Alg8 & NP_001007028.1 & XP_721736.1 & $41 \%$ & $80 \%$ \\
\hline $\begin{array}{l}\text { Dol-PP-Glc: } \\
\text { Dol-PP-GlcNAc }{ }_{2} \mathrm{Man}_{9} \mathrm{Glc}_{2} \alpha 1,2 \text {-glucosyltransferase }\end{array}$ & Alg10 & NP_116223.3 & XP_714677.1 & $32 \%$ & $96 \%$ \\
\hline \multirow[t]{5}{*}{ Post flipping chaperone } & Rft1 & NP_443091.1 & XP_717469.1 & $27 \%$ & $85 \%$ \\
\hline & RBPH1/Ost1 & NP_002941.1 & XP_714694.1 & $27 \%$ & $85 \%$ \\
\hline & DAD1/Ost2 & NP_001335.1 & XP_714366.1 & $40 \%$ & $81 \%$ \\
\hline & N33/Ost3 & NP_006756.2 & XP_721902.1 & $23 \%$ & $77 \%$ \\
\hline & Ost4 & NP_001128165.1 & EEQ47486.1 & $39 \%$ & $51 \%$ \\
\hline \multirow[t]{5}{*}{ OST components } & IAP/Ost6 & NP_115497.4 & XP_716090.1 & $22 \%$ & $84 \%$ \\
\hline & RIBIIR/SwpI & NP_002942.2 & XP_721287.1 & $26 \%$ & $58 \%$ \\
\hline & OST48 /Wbp1 & NP_005207.2 & XP_713903.1 & $24 \%$ & $91 \%$ \\
\hline & STT3A/Stt3 & NP_001265432.1 & XP_722527.1 & $56 \%$ & $94 \%$ \\
\hline & STT3B & NP_849193.1 & & $57 \%$ & \\
\hline Folding Sensor & UGGT1/Kre5 & NP_064505.1 & XP_719987.1 & $60 \%$ & $57 \%$ \\
\hline \multicolumn{6}{|l|}{ Glycosidases } \\
\hline Glucosidase I & MOGS/Cwh41 & NP_001139630.1 & ABB97046.1 & $29 \%$ & $91 \%$ \\
\hline \multirow{2}{*}{ Glucosidase II } & GANAB/Rot2 & NP_938148.1 & XP_716812.1 & $38 \%$ & $98 \%$ \\
\hline & GLU2B/Gtb1 & NP_002734.2 & XP_717976.1 & $39 \%$ & $57 \%$ \\
\hline ER $\alpha 1,2$-mannosidase I & MAN1B1/MnsI & NP_057303.2 & XP_713641.1 & $45 \%$ & $77 \%$ \\
\hline
\end{tabular}

* Accession number at NCBI database.

** Identity and ${ }^{* * *}$ coverage from BLAST alignment between human and C. albicans homolog sequences, respectively.

The flippase that translocates Dol-PP-GlcNAc $2 \mathrm{Man}_{5}$ has not been identified yet in any organism, although a critical accessory protein in yeast, Rft1, and its human ortholog have been proposed to participate in this process $[9,10]$. Nonetheless, a recent work in Trypanosoma brucei, an early diverging eukaryote, has pointed that $\mathrm{Rft} 1$ is not the much sought after flippase, although it is critical for allowing maturation of the Dol-PP-GlcNAc ${ }_{2} \mathrm{Man}_{5}$ intermediate once it is flipped to the rER lumen [11]. A putative ortholog of Rtf1 has been also found in C. albicans (Table 1).

Once synthesized, the Dol-PP-GlcNAc ${ }_{2} \mathrm{Man}_{9} \mathrm{Glc}_{3}$ precursor glycan is transferred en bloc by the oligosaccharyl transferase complex (OST) to Asn residues by linkage to carboxamide nitrogens. The Asn residues targeted for $\mathrm{N}$ linked glycosylation are located, with rare exceptions, within the consensus sequence Asn-X-Ser/Thr (where X is any amino acid except proline) [12]. However, not all consensus sequences are $N$-linked glycosylated, because this protein modification is a co-translational process, and thus other factors are involved in selecting consensus sequences, such as accessibility of OST to the consensus sequence during the unfolded state of the protein. The OST complex has not been characterised in detail in C. albicans; however, the fungus encodes all the subunit orthologs found in S. cerevisiae OST, which is comprised of nine different transmembrane subunits: Wbp1, Swp1, Stt3, Ost1, Ost2, Ost3, Ost4, Ost5, 
and Ost6, where Stt3 is the catalytic subunit [13] (Table 1). Mammalian equivalents to yeast/C. albicans OST subunits are known and include: ribophorin I (Ost1) and II (Swp1), OST48 (Wbp1), defender against apoptotic cell death or DAD1 (Ost2), N33 (Ost3), magnesium transporter 1 (Ost6), and OST4 (Ost4) [14-16], (Table 1). In addition, two Stt3 protein orthologs (STT3A and STT3B) have been identified in plants, insects, and vertebrates $[15,17,18]$. The human STT3A isoform is primarily responsible for cotranslational modification of sequons when the nascent polypeptide enters the rER lumen. The STT3B isoform is less competent for cotranslational glycosylation, but mediates the posttranslational modification of skipped glycosylation sites in unfolded proteins [19]. The mammalian OST has been found in three complexes that exhibit different ribosome affinities and subunit compositions: OSTC(I), OSTC(II), and OSTC(III) [16]. Furthermore, two additional components found in the mammalian OST complex have been reported: KCP2 and DC2 $[16,20]$.

Once transference onto the protein is achieved, the pathway continues with the processing and maturation stage. Processing is carried out, in both human and C. albicans, by rER enzymes: the mannosyl oligosaccharide glucosidase I (MOGS/Cwh41) that removes the outermost $\alpha 1,2$ glucose unit, and the mannosyl oligosaccharide glucosidase II which trims the following $\alpha 1,3$-glucose residue exposing the Glc $_{1} \mathrm{Man}_{9}$ GlcNAc 2 epitope [21] (Figure 1). In humans/ Candida, glucosidase II is a heterodimer composed of two subunits, the hydrolytic $\alpha$-subunit (GANAB/Rot2) and the $\beta$ subunit (GLU2B/Gtb1), see Table 1.

The $\mathrm{Glc}_{1} \mathrm{Man}_{9} \mathrm{GlcNAc}_{2}$ epitope is a key point of ER quality control of glycoproteins, as it binds to the calnexin/calreticulin (CNX/CRT) lectin that is a folding sensor associated to ERp57. At this point, glucosidase II removes the last glucose residue and, if correctly folded, the glycoprotein exits the rER after the $\alpha 1,2$-mannosidase removes one Man residue from the middle branch of the $N$-linked glycan core, generating GlcNAc${ }_{2} \mathrm{Man}_{8}$ (Figure 1). If the protein is misfolded, the glycan is reglucosylated by the action of the UGGT1 glucosyltransferase in humans and its ortholog Kre5 in C. albicans [22]. UGGT is a conformational sensor, regenerating the acceptor substrate for the calnexin/calreticulin lectin, starting a new deglucosylation step by glucosidase II. This cycle continues until the protein is correctly folded or targeted for ER-associated degradation [23].

In contrast to Candida, humans code for an endomannosidase (MANEA) located in the Golgi/ERGIC compartment that provides a glucosidase I and II independent pathway for $N$-linked glycan maturation. MANEA is able to remove the inner most Glc residue along with the Man residue attached to it, generating the $\mathrm{GlCNAc}_{2} \mathrm{Man}_{8}$ structure (Figure 1).

2.1. The Fate of GlcNAc${ }_{2} \mathrm{Man}_{8}$ in Humans. The further processing of the GlcNAc${ }_{2} \mathrm{Man}_{8}$ structure is the divergence point between humans and C. albicans (Figure 1). In humans, the $N$-linked glycans are processed by Golgi-resident mannosidase IA, IB, and IC, which have different hydrolytic patterns but all generate $\mathrm{Man}_{5} \mathrm{GlcNAc}_{2}$. This glycan is then acted upon by glycosyltransferase GlcNAcT-I to generate a GlcNAcMan $_{5}$ GlcNAc $_{2}$ structure that is acted upon by type II $\alpha$-mannosidases. The type II $\alpha$-mannosidases include the Golgi mannosidase II (MAN2A1), and in some cell types, additional mannosidases MAN2A2 and mannosidase III have been described as bypassing enzymes when mannosidase II fails to hydrolyse the $N$-linked glycan core [24-26]. The type II $\alpha$-mannosidases remove the terminal $\alpha 1$-3Man and $\alpha 1-6$ Man residues allowing addition of a second GlcNAc residue to give way to complex glycans. The GlcNAc residues can be extended with additional monosaccharide linkages involving galactose, fucose, or sialic acid residues. Furthermore, the hybrid and complex $N$-linked glycans found in humans may exist with two or more GlcNAc-bearing branches or antennae. In forming multiantennary $N$-linked glycan structures, GlcNAc residues may be added to the trimannosyl core by six different GlcNAc transferases (I-VI) [27]. If type II $\alpha$-mannosidases do not act or GlcNAcT-III bisects the GlcNAcMan ${ }_{5} \mathrm{GlcNAc}_{2}$ structure, hybrid glycans are then generated (Figure 1) [28].

In animals, $N$-linked glycans are terminated by sialic acid [29] in $\alpha 2,3-, \alpha 2,6-$, or $\alpha 2,8$ - linkages by specific sialyltransferases [30]. In humans, sialic acid is mostly of the $N$ acetylneuraminic acid form, in contrast to most mammalian species, where a mixture of $N$-glycolylneuraminic acid and $N$-acetylneuraminic acid is generally found. Sialic acid can be further modified by acetylation or sulphation [31]. This monosaccharide in view of its terminal position, linkages, and negative charge has been an important element in the evolution of animal glycan function [32]. Although $\alpha 2,3-$ and $\alpha 2,6$ - sialic acid have been identified in the cell wall of $C$. albicans $[33,34]$, no ortholog to vertebrate sialyltransferase or ability to synthesize sialic acid has been characterized in this fungus [35]. However, evidence of sialic acid synthesis has been reported in Aspergillus fumigatus [36] and C. neoformans, where sialyltransferase activity has been identified [37].

Another frequent modification of human $N$-linked glycans not seen in $C$. albicans is $\alpha 1,6$ - core fucosylation of the first GlcNAc residue, as well as terminal fucosylation on Gal or GlcNAc residues [38]. Nonetheless, fucose has been identified as a component of the cell wall of C. albicans [33] and binds the UEA-I lectin that is specific for L-fucose, more particularly to $\alpha 1,2$-fucose. UEA-I binding was associated with increased adherence to epithelial cells [39]. Recently mass spectrometry identified $\alpha 1,6$-fucose residues in oligomannosylated $N$-linked glycans of the fungi Cantharellus cibarius [40]. This raises the question on how this type of glycans are presented in the surface of mushrooms, as no FUT8 family member of fucosyltransferases responsible for this linkage has been identified in yeast nor mushrooms [38]. Although little is known about fucosylation and sialylation mechanisms in C. albicans or fungi in general, more information is hinting at their role in pathological human host interactions through molecular mimicry.

Furthermore, human $N$-glycans can be phosphorylated to target glycoproteins to the lysosomes, through interaction with the Man-6-P receptor [41]. Phosphorylation occurs 
by modification of the GlcNAc ${ }_{2} \mathrm{Man}_{8}$ structure by a UDPGlcNAc-dependent GlcNAc-1-phosphotransferase (Figure 1) [42]. A GlcNAc phosphodiester is added to $N$-linked glycans on one of three mannose residues on the arm with the $\alpha 1,6$ linkage to the core mannose. A second phosphodiester can then be added to the other side of the $N$-glycan or onto other mannose residues (Figure 1). Afterwards, the phosphodiester glycosidase in the trans-Golgi removes the GlcNAc to generate Man-6-P residues. The phosphate residues partially block the action of processing mannosidases, maintaining the $\mathrm{N}$ glycans in an oligomannosyl form. Some hybrid $N$-linked glycans with Man-6-P can also be found. This sorting system of soluble proteins does not exist in C. albicans or other yeast species, but interestingly they contain the gene MRL1, which seems to be the ortholog of that encoding the human Man-6$P$ receptor [43].

2.2. The Fate of $\mathrm{GlcNAc}_{2} \mathrm{Man}_{8}$ in C. albicans. In C. albicans, the $N$-linked glycan $\mathrm{GlcNAc}_{2} \mathrm{Man}_{8}$ is modified by proteins that have no human orthologs (see Table 2). The GlcNAc $\mathrm{Man}_{8}$ core is recognised by Och1, an $\alpha 1,6-$ mannosyltransferase that adds the first mannose residue of the $N$-linked glycan outer chain [44] (Figure 1). This mannose residue works as a molecular primer to build the $\alpha 1,6$-mannose backbone, which in $S$. cerevisiae is elongated by the M-Pol I complex (a heterodimer composed of Mnn9 and Van1) that adds 3 to 7 mannose residues [45] and then by M-Pol II, a multimeric complex composed of Mnn9, Anp1, Mnn10, Mnn11, and Hocl $[46,47]$ (Figure 1). Both, in vivo and in vitro studies have shown that Mnn10 and Mnnll contribute to most of the $\alpha 1,6$-mannosyltransferase activity of M-Pol II [47]. Thus far, there is only experimental evidence about Mnn9 role in C. albicans [48]; however, the encoding genes for all members of both complexes are present within $C$. albicans genome and it is likely they work as described in the baker yeast.

Parallel to this process, the $\alpha 1,6$-mannose polymer works as a molecular scaffold where branches of $\alpha 1,2$-mannose residues are added by Mnn5 [49, 50]. These are further elongated by the mannosyltransferases Mnt4 and Mnt5 [51], and members of the MNN2-like gene family [52]. In $S$. cerevisiae, the branches are terminated with $\alpha 1,3$-mannose residues added by action of the mannosyltransferase Mnn1 [53]. In C. albicans, these mannose residues are also present and are likely to be incorporated to glycans via the same protein [54]; however, it is most frequent that the $\alpha 1,2$ mannose branches are further decorated and capped with $\beta 1,2$-mannose units [55]. The $\beta 1,2$-mannosylation is characteristic of this pathogenic yeast species and is carried out by members of the BMT gene family [56].

Another decoration attached to the $\alpha 1,2$-mannose branches is the phosphomannan, which is a mannose residue attached to the $N$-linked glycan by a phosphodiester bond (Figure 1). This phosphorylation is not related to that found in humans and is partially synthesized by phosphomannosyltransferases Mnt3 and Mnt5 [51]. The identity of the enzymes involved in the addition of the rest of the phosphomannan remains unknown, although it is likely that members of the MNN4-like family contribute to this activity $[57,58]$. As the $N$-linked glycan, the phosphomannan can be further $\beta 1,2$-mannosylated with up to $14 \beta 1,2$-mannose units [59], by action of Bmt2, Bmt3, and Bmt4 [56].

2.3. Functions of N-Linked Glycans in Humans. The N-linked glycans associated to glycoproteins participate in the calnexin/calreticulin ER quality control system of glycoprotein folding [60]. Furthermore, $N$-linked glycans are involved in protein stabilization and trafficking and serve as moieties recognized by receptors, thereby modulating binding by increasing or decreasing affinity. The $N$-linked glycans play from trivial to essential roles in glycoprotein function and are involved in most, if not all, cellular processes. There is clear evidence that this posttranslational modification is essential for homeostasis in multicellular organisms as has been demonstrated by clinical phenotypes, mostly multisystemic, of patients affected by congenital disorders of glycosylation, indicating that $N$-linked glycan integrity is required for normal tissue function [61].

2.4. Functions in C. albicans. The $N$-linked mannans are essential for $C$. albicans viability, as demonstrated by treatment with tunicamycin, a drug that inhibits the action of Alg7 during $N$-linked glycan core synthesis [62]. Furthermore, they are quite important for cell fitness: defects in either the processing step by rER $\alpha$-glycosidases or elongation by Golgi mannosyltransferases lead to longer duplication times, swollen cells, inability to perform proper cell separation, abnormal colony morphology, and impaired ability to undergo dimorphism $[21,44,51,63]$. These pleiotropic defects are likely consequences of loss of the cell wall plasticity: mutant cells with defects in the $N$-linked mannan biosynthesis have rearrangements in the wall composition, including low mannan levels and high chitin and glucan contents, which led to increasing the sensitivity to cell wall perturbing agents such as tunicamycin, Congo red, Calcofluor white, hygromycin B, and caffeine [4, 21, 44, 50-52, 63]. Protein modification by $N$-linked mannans also modulates protein secretion, but surprisingly in a negative form, as shown in mutants lacking rER $\alpha$-glycosidases, which display increased cell wall protein content [21]. In addition, biofilm formation seems to depend on $N$-linked mannans, as shown by the inability of tunicamycin-treated cells to form this kind of microbial consortiums [64]. Finally, and most important, $N$ linked mannosylation is required for normal cell adhesion and virulence $[4,21,44,50,51,63,65-69]$. The extent to which fucosylation and sialylation play a role in pathogenicity through the adhesion to the host surface, particularly extracellular matrix components, still requires further characterization in C. albicans.

\section{The O-Linked Mannosylation Pathway}

In contrast to $C$. albicans that only synthesizes $O$-linked mannosyl glycans (O-Man), six additional types of $O$-linked glycans are found in humans, and are classified based on the first sugar attached to the amino acid residue: GlcNAc, GalNAc, galactose, xylose, glucose, or fucose. 
TABLE 2: C. albicans nonhomologous proteins involved in the $\mathrm{N}$-linked, $\mathrm{O}$-linked, and GPI-anchor pathways.

\begin{tabular}{|c|c|c|}
\hline Protein function & Protein & ID $^{*}$ \\
\hline \multicolumn{3}{|l|}{ N-glycosylation } \\
\hline Golgi $\alpha 1,6$-mannosyltransferase & Och1 & XP_716632 \\
\hline \multirow{2}{*}{ Golgi $\alpha 1,6$-mannosyltransferase complex M-Pol I } & Mnn9 & XP_716624.1 \\
\hline & Van1 & XP_719719.1 \\
\hline \multirow{5}{*}{ Golgi $\alpha 1,6$-mannosyltransferase complex M-Pol II } & Mnn9 & XP_716624.1 \\
\hline & Anp1 & XP_714464.1 \\
\hline & Mnn10 & XP_713339.1 \\
\hline & Mnn11 & XP_721427.1 \\
\hline & Hocl & XP_716693.1 \\
\hline \multirow{3}{*}{ Golgi $\alpha 1,2$-mannosyltransferases } & Mnn5 & XP_713952.1 \\
\hline & Mnt4 & XP_711944.1 \\
\hline & Mnt5 & XP_712920.1 \\
\hline Golgi $\alpha 1,3$-mannosyltransferases & Mnn1 & XP_720587.1 \\
\hline \multirow{4}{*}{ Golgi $\beta 1,2$-mannosyltransferases } & Bmt1 & XP_719878.1 \\
\hline & Bmt2 & XP_710865.1 \\
\hline & Bmt3 & XP_717972.1 \\
\hline & Bmt4 & XP_719173.1 \\
\hline \multirow{2}{*}{ Golgi phosphomannosyltransferase } & Mnt3 & XP_710267.1 \\
\hline & Mnt5 & XP_713952.1 \\
\hline \multicolumn{3}{|l|}{ O-glycosylation } \\
\hline Protein $O$-mannosyltransferase & Pmt1 & XP_716926.1 \\
\hline Protein $O$-mannosyltransferase & Pmt5 & XP_719311.1 \\
\hline Protein $O$-mannosyltransferase & Pmt6 & XP_717283.1 \\
\hline Golgi $\alpha 1,2$-mannosyltransferases & Mnt1 & XP_721742.1 \\
\hline Golgi $\alpha 1,2$-mannosyltransferases & Mnt2 & XP_721740.1 \\
\hline \multicolumn{3}{|l|}{ GPI anchor } \\
\hline$\alpha 1,2$-mannosyltransferase (brain and colon) & Smp3 & XP_715268.1 \\
\hline$O$-acyltransferase & Gup1 & XP_722305.1 \\
\hline
\end{tabular}

${ }^{*}$ Accession number at NCBI database.

The O-Man glycans were identified on brain proteoglycans more than 30 years ago [70], and the $O$-mannosylation of $\alpha$-dystroglycan $(\alpha \mathrm{DG})$ has been the most studied. In contrast to $C$. albicans, human O-Man glycans contain only one mannose residue (linked to the protein) and are extended with other monosaccharides (Figure 2). In C. albicans, the $O$ Man glycans are composed of up to five mannose residues [71]. Most of the mammalian $O$-mannosyl glycans are variations of the common tetrasaccharide core NeuAc $\alpha 2-3 \mathrm{Gal} \beta 1$ $4 \mathrm{GlcNAc} \beta 1$-2Man $\alpha 1-\mathrm{Ser} / \mathrm{Th}$, although branched structures with 2,6-di-substituted mannose (GlcNAc-linked $\beta 1,2$ and $\beta 1,6)$ have been described in brain glycoproteins [72].

In humans, the first mannose residue is added in the rER by protein-O-mannosyl-transferase 1 (POMT1) [73] and 2 (POMT2) [74], homologous to C. albicans Pmt4 and Pmt2, respectively (Table 3 ). Both enzymes perform their function in an essential complex that uses Dol-P-Man as sugar donor [75]. In humans, elongation of O-Man glycans is initiated in the Golgi complex by transfer of GlcNAc to the Man residue in the $2-\mathrm{OH}$ position, mediated by the protein-O-mannosyl $N$-acetylglucosaminyltransferase 1 (POMGnT1) that uses
UDP-GlcNAc as donor substrate (Figure 2) [76]. Alternatively, $N$-acetylglucosaminyltransferase IX (GnT-IX) can make branched structures transferring GlcNAc in $\beta 1,6-$ linkage to the O-Man glycan [22]. Further enzymes directly involved in the elongation of $O$-Man glycans remain to be identified among families of $\beta 1,4$-galactosyltransferases and $\alpha 2,3$-sialyltransferases.

Another $O$-linked glycan structure (GalNac $\beta 1$ 3 GlcNAc $\beta 1-4$ Man $\alpha 1$-Ser/Thr) has been reported in $\alpha \mathrm{DG}$ [77] (Figure 2). This structure is further phosphorylated in the 6-position of $O$-mannose by the action of the Protein-O-mannose kinase (POMK) [78]. The LARGE and LARGE2 bifunctional glycosyltransferases act on the phosphomannose structure producing repeating units of [-3-xylose- $\alpha 1,3$-glucuronic acid- $\beta 1-]$ (Figure 2) $[79,80]$. Two other proteins, FUKUTIN and FKRLP, with glycosyltransferase characteristics, are also involved in the formation of human O-Man glycans, but their function remains unknown.

As in humans, in C. albicans, this pathway starts in the rER and finalises in the Golgi complex. The synthesis 
TABLE 3: Human and C. albicans homolog proteins involved in the $O$-mannosylation pathway.

\begin{tabular}{|c|c|c|c|c|c|}
\hline Protein function & Protein $\mathrm{H} / \mathrm{Ca}$ & Human ID* & Candida ID* & $\mathrm{Id}^{* *}$ & $\operatorname{Cov}^{* * *}$ \\
\hline Protein $O$-mannosyltransferase & POMT2/Pmt2 & NP_037514.2 & XP_719907.1 & $36 \%$ & $89 \%$ \\
\hline Protein $O$-mannosyltransferase & POMT1/Pmt4 & NP_001129586.1 & XP_714280.1 & $34 \%$ & $80 \%$ \\
\hline
\end{tabular}

*Accession number at NCBI database.

** Identity and ${ }^{* * *}$ coverage from BLAST alignment between human and C. albicans homolog sequences, respectively.
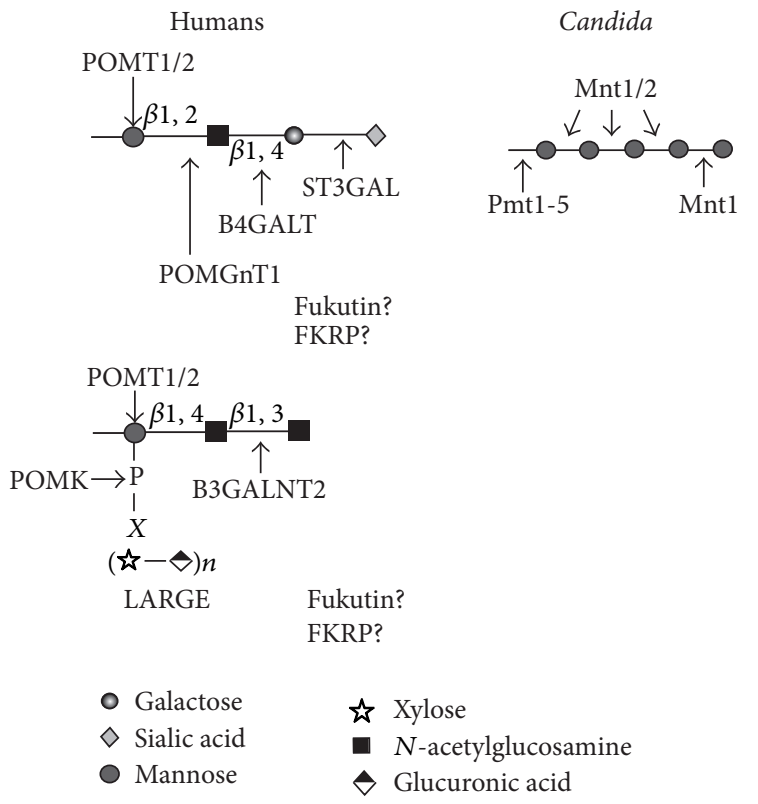

FIgURE 2: The O-linked mannosylation pathway. Human $O$ linked mannosyl glycans have been characterized mainly in alphadystroglycan where POMT1/2 add the first mannose residue that is further extended with other monosaccharides by the action of glycosyltransferases. The mannose residue can also be phosphorylated by the action of POMK, allowing further modification by disaccharide repeats of xylose and glucuronic acid synthesized by LARGE and LARGE2. Fukutin and FKRP genes are needed for correct glycosylation, but their roles remain to be clearly defined. In C. albicans, mannosylation involves the addition of the first mannose residue by the action of Pmt1-5, and that is further extended with four additional mannose residues by the action of Mnt 1 and Mnt2.

begins with the addition of one $\alpha$-linked mannose residue to Ser or Thr residues via an ester bond. This reaction takes place in the rER lumen and is catalysed by the proteinmannosyl transferases that use Dol-P-man as sugar donor [81]. This enzyme activity is performed by a family composed of five members that are subclassified in three groups: the Pmt1 (Pmt1/5), Pmt2 (Pmt2/6), and Pmt4 subfamilies [82] (Figure 2). The proteins encoded by these subfamilies do not have redundant activity in vivo, as each member has specific substrates [81-83]. In addition, these enzymes interact among them generating protein-protein interactions. In S. cerevisiae, Pmt1 interacts in vivo with Pmt2, and combined disruption of PMT1 and PMT2 results in more than $90 \%$ less enzyme activity in vitro [84]. Another predominant complex includes Pmt5 and Pmt3, but in the absence of Pmt5, Pmt 3 can form a complex with Pmt1, and Pmt2 can form a complex with Pmt5 when Pmt3 is disrupted [84]. Pmt1, Pmt5, and Pmt6 have no human orthologs (Table 2).

Once the glycoproteins are transported to the Golgi complex, the $O$-linked glycans are further elongated by the Golgi $\alpha 1,2$-mannosyltransferases Mnt1 and Mnt2 that have redundant activities to fully elongate the glycans $[71,85]$. This mannan structure can also be phosphomannosylated, and in fact, the phosphosugar attached to $O$-linked mannans represents about $20 \%$ of total cell wall phosphomannan content [21]. However, the machinery involved in this process is different of that described for $\mathrm{N}$-linked mannans, as Mnt3 and Mnt5 do not add phosphomannose to O-linked mannans [51]. Mnt proteins have no human orthologs (Table 2).

As mentioned before, sialic acid has been described in $C$. albicans [33,36], and sialidase treatment has been shown to increase binding of the peanut agglutinin that has specificity for the Gal $\beta 1,3 \mathrm{GalNAc}$ sequence present in human Core $1 \mathrm{O}$-glycans which has not been described in C. albicans. This suggests that sialic acid could be part of C. albicans $O$-linked mannans and the presence of uncharacterized galactosyltransferases.

3.1. Functions in Humans. The best characterized mammalian $O$-linked Man glycoprotein is $\alpha \mathrm{DG}$ (Figure 2). This protein is a glycosylated peripheral membrane protein involved in linking the cytoskeleton of neurons and muscle cells to the basal lamina through interactions with extracellular proteins; glycosylation of $\alpha \mathrm{DG}$ is essential for its function [86]. To date, mutations in seven glycosyltransferase or glycosyltransferase-like genes have been reported to affect the $O$-linked mannosylation pathway and are causative for various forms of autosomal recessive congenital muscular dystrophies associated with variable brain and ocular abnormalities [87]. As it was mentioned earlier, $O$-Man glycans in humans are not highly mannosylated structures; they only possess a single Man residue. This divergence is functionally important in the immune systems recognition of pathogenic yeast and fungal microorganisms, including C. albicans. Highly mannosylated structures, as those found in yeast and fungi, are recognized as foreign by both circulating antibodies and elements of the complement system, including both the classical and alternative pathways [88].

3.2. Functions in C. albicans. Loss of PMT2 or combined disruption of PMT1 and PMT4 led to nonviable cells, indicating that $O$-linked mannosylation is essential for growth and cell viability [81]. In addition, incomplete $O$-linked mannan elaboration has been associated with rearrangements in the cell wall composition, increasing sensitivity to cell wall perturbing agents, defects in morphogenesis, reduced 
tissue adhesion, defective biofilm formation, and virulence attenuation [71, 81, 89-91].

The O-linked mannans are key cell wall elements during the $C$. albicans sensing by immune cells. This cell wall component is sensed by TLR4 receptor [88], and loss of either $O$-linked mannans or TLR4 receptor has a negative impact on cytokine production by human PBMCs [88], on the proinflammatory response of oral epithelial cells [92], and on yeast killing by human polymorphonuclear cells [93]. Indeed, $\mathrm{TLR}^{-/-}$knockout mice are more susceptible to infections caused by $C$. albicans due a defective immune response against the fungus $[94,95]$. Furthermore, it has been demonstrated that simultaneous stimulation of dectin-1 and either TLR2 or TLR4 significantly enhances cytokine production in both human monocytes and macrophages [96, 97]. Therefore, it has been hypothesized that recognition of $O$-linked mannans plays a pivotal role, along with $\beta 1,3$-glucan sensing, in the establishment of a protective anti-Candida immune response.

However, the relevance of $O$-linked mannans during C. albicans sensing is not the same for different kinds of immune cells, as yeast cells lacking both MNT1 and MNT2, and therefore expressing truncated $O$-linked mannans at the cell wall surface [71], are as good as the wild type control cells to stimulate binding and cytokine production by human dendritic cells [98]. Moreover, there are some $C$. albicans strains whose immune sensing is independent of recognition via TLR4, suggesting that the fungus might be able to modulate the production of this cell wall component [99].

\section{The GPI Anchors}

The GPI anchors are complex structures that comprise a phospholipid tail, a glycan core, and a phosphoethanolamine linker (Figure 3). This structure is attached to the C-terminus of some eukaryotic proteins, allowing their anchoring to cell membranes or the wall. The core glycan, $\operatorname{mannose}(\alpha 1-2)$ mannose ( $\alpha 1-6)$ mannose ( $\alpha 1-4)$ glucosamine ( $\alpha 1-6)$ myo-inositol is highly conserved in eukaryotes, but it can be modified with other residues such as mannose, phosphoethanolamine (Etn-P), galactose, sialic acid, and others. The GPI synthetic pathway (Figure 3) initiates on the cytoplasmic side of the rER with the transfer of GlcNAc from the UDPGlcNAc donor to phosphatidylinositol. This step requires several proteins that form complex (GPI-GnT), PIG-A/Gpi3, PIG-C/Gpi2, PIG-H/Gpi15, PIG-P/Gpi19, PIG-Q/Gpil, and PIG-Y/Eril (mammals/yeast) [100-107]; see Table 4.

Next, GlcNAc-PI is deacetylated by PIG-L/Gpil2, generating GlcN-PI [108], which requires crossing the rER membrane to continue the synthetic pathway within the lumen. This transport, as in the other protein modification described above, is carried out by a rER flippase. Then, inositol acylation takes place due to the acyltransferase activity of PIG-W/Gwt1, being the donor acyl-CoA $[109,110]$. GPI mannosylation takes place using Dol-P-Man as mannose donor and begins with action of the mannosyltransferase PIG-M/Gpil4 in complex with PIG-X/Pbn1 that adds the first mannose $(\alpha 1,4-$ linked) to GlcN [111]. The second ( $\alpha 1,6$-linked) and third

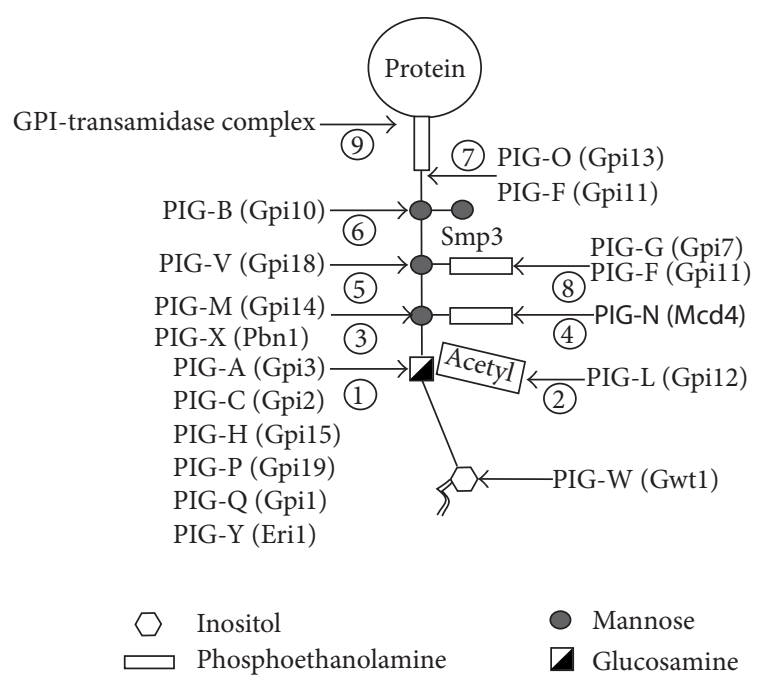

FIgURE 3: The GPI anchorage pathway. GPIs are glycolopids that act as a membrane anchor for many cell surface proteins and are composed of an inositol molecule that is sequentially modified in the ER with a Man3GlcN glycan and phosphoethanolamine groups. Numbers show sequential steps for the synthesis of a Man3GlcN glycan bearing GPI. A GPI-transamidase complex acts upon the phosphoethanolamine group linked to the terminal mannose to add the surface protein. The C. albicans Smp3 adds a fourth mannose residue that is essential for protein transfer; but in humans it is not essential for transamidation and its expression appears to be restricted to brain and colon.

( $\alpha 1,2$-linked) mannose units are transferred by PIG-V/Gpi18 and PIGB/Gpil0 mannosyltransferases, respectively [112115]. The enzyme Smp3 catalyses the addition of a fourth mannose residue ( $\alpha 1,2$-linked) to Man-3 of the glycan core, being an essential step in yeast and Candida cells, as it is required for subsequent attachment of phosphoethanolamine $[116,117]$. Mammalian cells mostly transfer trimannosylGPIs to proteins and do not require the addition of a fourth mannose residue, but a human ortholog of the yeast mannosyltransferase Smp3 that adds a fourth, $\alpha 1,2$-linked Man to trimannosyl GPI precursors has been identified, displaying high expression in brain and colon, suggesting that $\mathrm{Man}_{4}$-GPIs elaboration could be tissue-specific [117]. In C. albicans, Smp3 and is essential for viability and has been proposed to be a potential antifungal target [118].

An Etn-P unit can be attached to the first mannose of the glycan core as a side branch by PIG-N/Mcd4 and also to the second mannose by a complex of PIG-F/Gpill and PIGG/Gpi7 [119-121]. Finally, a moiety of Etn-P is added to the third mannose of the core, being this residue the one bound to the protein through an amide link. A transferase association between PIG-O/Gpil3 and PIG-F/Gpill is responsible for this step $[122,123]$. The GPI synthetic pathway is highly conserved, but GPIs can be further modified in the lipid and glycan moieties depending on genus, species, and protein type [124].

The GPI-anchored proteins have a C-terminal sequence that directs the attachment of a GPI anchor. The removal of the C-terminal GPI signal sequence and its replacement 
TABLE 4: Human and C. albicans homologous proteins involved in GPI glycosylation.

\begin{tabular}{|c|c|c|c|c|c|}
\hline Protein function & Protein $\mathrm{H} / \mathrm{Ca}$ & Human ID* & Candida ID* & $\mathrm{Id}^{* *}$ & $\operatorname{Cov}^{* * *}$ \\
\hline \multirow{6}{*}{ GlcNAc-PI synthesis } & PIG-A/Gpi3 & NP_002632.1 & XP_717439.1 & $49 \%$ & $94 \%$ \\
\hline & PIG-C/Gpi2 & NP_714969.1 & XP_717493.1 & $31 \%$ & $90 \%$ \\
\hline & PIG-H/Gpil5 & NP_004560.1 & XP_718197.1 & $33 \%$ & $44 \%$ \\
\hline & PIG-P/Gpi19 & NP_710149.1 & XP_714916.1 & $33 \%$ & $37 \%$ \\
\hline & PIG-Q/Gpil & NP_683721.1 & XP_714683.1 & $30 \%$ & $42 \%$ \\
\hline & PIG-Y/Eril & NP_001036081.1 & XP_715355.1 & $64 \%$ & $9 \%$ \\
\hline GlcNAc-PI de-N-acetylation & PIG-L/Gpil2 & NP_004269.1 & XP_723585.1 & $29 \%$ & $55 \%$ \\
\hline Inositol acylation & PIG-W/Gwt1 & NP_848612.2 & XP_712842.1 & $28 \%$ & $99 \%$ \\
\hline$\alpha 1,6$-mannosyltransferase & PIG-M/Gpil4 & NP_660150.1 & XP_722653.1 & $38 \%$ & $94 \%$ \\
\hline$\alpha 1,6$-mannosyltransferase & PIG-X/Pbn1 & NP_001159776.1 & XP_716695.1 & $19 \%$ & $24 \%$ \\
\hline Etn-P transfer to Man-1 & PIG-N/Mcd4 & NP_789744.1 & XP_716313.1 & $37 \%$ & $95 \%$ \\
\hline$\alpha 1,6$-mannosyltransferase & PIG-V/Gpi18 & NP_060307.2 & XP_713712.1 & $24 \%$ & $82 \%$ \\
\hline$\alpha 1,2$-mannosyltransferase & PIG-B/Gpil0 & NP_004846.4 & XP_721904.1 & $31 \%$ & $97 \%$ \\
\hline Etn-P transfer to Man-3 & PIG-O/Gpil3 & NP_001188413.1 & XP_720956.1 & $38 \%$ & $53 \%$ \\
\hline Etn-P transfer to Man-2 and 3 & PIG-F/Gpill & NP_002634.1 & XP_720511 & $35 \%$ & $44 \%$ \\
\hline Etn-P transfer to Man-2 & PIG-G/Gpi7 & NP_001120650.1 & XP_710743.1 & $38 \%$ & $47 \%$ \\
\hline$\alpha 1,2$-mannosyltransferase & Smp3 & NP_079439.2 & XP_715333.1 & $26 \%$ & $91 \%$ \\
\hline Etn-P transfer to Man-2 & Gpi7 & NP_001120650.1 & EEQ42670.1 & $40 \%$ & $72 \%$ \\
\hline \multirow[t]{5}{*}{ GPI transamidase } & PIG-K/Gpi8 & NP_005473.1 & XP_711741.1 & $56 \%$ & $78 \%$ \\
\hline & GAA1 & NP_003792.1 & XP_710522.1 & $35 \%$ & $49 \%$ \\
\hline & PIG-S/Gpil7 & NP_149975.1 & XP_716135.1 & $27 \%$ & $48 \%$ \\
\hline & PIG-T/Gpil6 & NP_057021.2 & XP_720200.1 & $29 \%$ & $94 \%$ \\
\hline & PIG-U/Cdc91 & NP_536724.1 & XP_720773.1 & $24 \%$ & $92 \%$ \\
\hline Inositol deacylation & PGAP-1/Bst1 & NP_079265.2 & XP_713657.1 & $31 \%$ & $75 \%$ \\
\hline$s n-2$ deacylation & PGAP3/Per1 & NP_219487.3 & XP_712020.1 & $26 \%$ & $95 \%$ \\
\hline$s n-2$ acylation & PGAP2/Cwh43 & NP_001269969.1 & XP_717850.1 & & \\
\hline
\end{tabular}

* Accession number at NCBI database.

${ }^{* *}$ Identity and ${ }^{* * *}$ coverage from BLAST alignment between human and C. albicans homologous sequences, respectively.

with GPI on the lumen of rER are catalyzed by the GPI transamidase (GPIT), which is a complex consisting of the membrane proteins PIG-K/Gpi8, GAA-1, PIG-S/Gpi-17, PIGT/Gpi16, and PIG-U/Cdc91 $[125,126]$. In the first step of the GPIT-catalyzed reaction, the GPI signal sequence is cleaved and the newly generated $\alpha$-carbonyl group is attached via a thioester linkage to the PIG-K subunit of GPIT. Nucleophilic attack on the activated carbonyl by the amino group of the terminal EtN-P residue of GPI regenerates GPIT and yields a GPI-anchored protein.

After transfer, the inositol group introduced before mannosylation of the GPI precursor is removed in humans and yeast by the orthologous PGAP1/Bstl deacylase ER proteins [127]. Yeast is able to remodel the shorter acyl chains of the diacylglycerol shortly after transfer to either baselabile $\mathrm{C}_{26: 0} / \mathrm{C}_{26: 0}$ diacylglycerols or to a base-stable ceramide consisting of $\mathrm{C}_{18: 0}$ phytosphingosine and a hydroxy- $\mathrm{C}_{26: 0}$ fatty acid. The remodeling initiates with the removal by PGAP3/Perl of the acyl chain at the $s n-2$ position of the diacylglycerol $[128,129]$. PGAP3-dependent removal of unsaturated fatty acyl chains at the sn-2 position occurs predominantly in the Golgi, whereas Perl activity is located in the rER.
Next, a $\mathrm{C}_{26: 0}$ acyl chain is introduced at $s n-2$ by the $\mathrm{O}$-acyltransferase Gupl that is the only enzyme involved in GPI anchor synthesis in C. albicans that has no human ortholog [130]. The mammalian PGAP2 protein is involved in the subsequent introduction of a saturated $\left(\mathrm{C}_{18: 0}\right)$ fatty acid at $s n-2$ [131]. Mutations in the yeast gene that encodes a homolog of PGAP2, CWH43, albeit a much larger protein, cause cell wall abnormalities consistent with defects in cell surface anchorage of GPI proteins. In mammals, remodeling at $s n-2$ requires prior inositol deacylation by PGAP1 [129]. The PGAP3- and PGAP2-dependent remodeling activities, in turn, are necessary for the GPI-anchored proteins to associate with lipid rafts.

4.1. Functions in Humans. The obvious role for GPI-anchors is the attachment of proteins to cell surface. Examples include cell surface receptors (e.g., folate receptor, CD14), cell adhesion molecules (e.g., neural cell adhesion molecule), cell surface hydrolases (e.g., alkaline phosphatase), and complement regulatory proteins (e.g., decay-accelerating factor [CD55]). Human diseases arise by failures in this posttranslational process, stressing its importance for proper function of human cells. The paroxysmal nocturnal hemoglobinuria is 
a consequence of lower surface expression of GPI-proteins, due to clonal acquired mutations in PIG-A [132]. Inherited mutation in the promoter region of PIG-M impairs the binding of the transcription factors, resulting in abrogation of GPI mannosylation, leading to propensity to venous thrombosis and seizures [133]. Other congenital diseases involving defective PIG anchoring have been recently described [134].

4.2. Functions in C. albicans. As in human cells, GPI synthesis is essential for S. cerevisiae growth $[101,135]$. C. albicans has 115 putative GPI-proteins, with diverse predicted functions, including adhesion to host tissues [136]. C. albicans GPI7 leads to an aberrant cell wall composition with increased chitin content and less protein abundance [137], while cells lacking Smp3 mannosyltransferase are nonviable [118]. Recently, it has been demonstrated that defects in GPI synthesis affect hypha growth [138]. Yadav et al. propose that Gpi2 and Gpil9 subunits of the GPI-GnT complex regulate ergosterol synthesis and RAS signaling, which explains the influence of GPI synthesis in the dimorphic switch [139]. Adhesins of the Als family are known to be GPI-proteins [140], so it is not surprising that virulence is attenuated in GPI mutants.

\section{The Glycosylation Pathways as Potential Drug Targets against Fungal Infections}

The information gathered in the last decades about the human glycosylation pathways has helped to differentiate the normal processes from those found in neoplastic cells, and these are now explored as potential strategies to treat cancer $[141,142]$. Since protein glycosylation is a key process for $C$. albicans fitness and virulence attributes $[4,143]$, it is assumed that the development of inhibitors for any of the glycosylation pathways may assist in treatment of candidiasis. Tunicamycin is one of the oldest $N$-linked glycosylation inhibitors that has been thoroughly characterised over the last decades. It affects the elaboration of the $N$-linked glycan core [144], and tunicamycin-treated cells of $C$. albicans lose the viability [21] and the ability to generate biofilms [64], making this molecule a potential anti-C. albicans drug. However, the UDP-N-acetylglucosamine, dolichol phosphate GlcNAc-1-P transferase, the molecular target of this compound, is equally sensitive in both human and fungal cells [64].

A promising strategy for treatment of C. albicans infections could be found in the rER glucosidase inhibitors, which have been used in the experimental control of some viruses [145-149]. We have previously shown that C. albicans cells require processing of the $N$-linked glycan core in order to elongate their $N$-linked mannans, and loss of either glucosidase I or II led to virulence attenuation [21]. Since the human cells have a bypassing strategy for glucosidase trimming via the endomannosidase enzyme activity, it is feasible to conceive the potential low cytotoxicity of these drugs on the host cells. Celgosivir [150], PBDNJ0804-a deoxynojirimycin derivative [149], and CM-10-18 [147] are rER glucosidase I inhibitors that could show anti-C. albicans activity.

The O-linked mannosylation pathway can also be targeted for drug design. It was recently demonstrated that the rhodanine-3-acetic acid derivative OGT2468 is a PMT inhibitor in S. cerevisiae [151] and that it likely affects the same biosynthetic pathway in C. albicans. Whether this compound affects or not the elaboration of $O$-linked Man glycoprotein in human cells remains to be addressed.

The enzymes involved in GPI synthesis are also potential targets to develop new antifungal drugs. Gepinacin and E1210 were found to inhibit the fungal acyltransferase Gwtl, impairing the growth of fungal pathogens. Despite the functional similarity, gepinacin has no effect on the mammalian ortholog PIG-W. Assays on C. albicans cells treated with gepinacin indicate that they overexpose $\beta$-glucans on the wall surface, which triggers a better macrophage response [152-154]. Development of Smp3 or Gup1 inhibitors would be of value in view of their nonessential nature or absence in humans, respectively.

\section{Conclusions}

Metazoa (animals) and fungi derive from a common ancestor that existed $\sim 1$ billion years ago, nonetheless the basis of protein glycosylation pathways is strikingly conserved in spite of this period. In this review, we can look at the common bases and differences that emerge when comparing glycosylation mechanisms in C. albicans and humans.

The study of $C$. albicans glycosylation machinery is an important step to identify pharmacological targets to treat local or systemic candidiasis. Ideal pharmacological targets are represented by those elements only present in Candida. In the $N$-linked glycosylation pathway at least 16 GTs participate in mannan synthesis and are not present in humans (see Table 2), making this pathway an attractive alternative for drug design. Thus far, some promising approaches have been done with glucosidase inhibitors, but their toxicity in human cells remains to be addressed. In addition, rER-mannosidase inhibitors could be used as an alternative approach, as fungal cells only contain one mannosidase class I within the rER, and its loss is associated with virulence attenuation [21].

The above data indicate that fungal glycosylation pathways are promising for inhibitory compound screening that are species specific, both because of the presence of many nonhomologous proteins identified in C. albicans, particularly in the $N$-glycosylation pathway, and also because of the presence of homologous proteins that have a low degree of identity. Further studies should focus on developing compounds to inhibit the essential functions of glycosylation pathways taking into account these facts.

\section{Conflict of Interests}

The authors declare that there is no conflict of interests regarding the publication of this paper.

\section{Acknowledgments}

Héctor M. Mora-Montes was supported by CONACyT (ref. CB2011/166860) and Universidad de Guanajuato. Iván Martínez-Duncker was supported by the Sociedad Latinoamericana de Glicobiología A.C. 


\section{References}

[1] B. Modrzewska and P. Kurnatowski, "Selected pathogenic characteristics of fungi from the genus Candida," Annals of Parasitology, vol. 59, no. 2, pp. 57-66, 2013.

[2] L. Lehle, S. Strahl, and W. Tanner, "Protein glycosylation, conserved from yeast to man: A model organism helps elucidate congenital human diseases," Angewandte Chemie-International Edition, vol. 45, no. 41, pp. 6802-6818, 2006.

[3] M. Aebi and T. Hennet, "Congenital disorders of glycosylation: genetic model systems lead the way," Trends in Cell Biology, vol. 11, no. 3, pp. 136-141, 2001.

[4] H. M. Mora-Montes, P. Ponce-Noyola, J. C. Villagómez-Castro, N. A. R. Gow, A. Flores-Carreón, and E. López-Romero, "Protein glycosylation in Candida," Future Microbiology, vol. 4, no. 9, pp. 1167-1183, 2009.

[5] A. J. Parodi, " $N$-glycosylation in trypanosomatid protozoa," Glycobiology, vol. 3, no. 3, pp. 193-199, 1993.

[6] J. Samuelson, S. Banerjee, P. Magnelli et al., "The diversity of dolichol-linked precursors to Asn-linked glycans likely results from secondary loss of sets glycosyltranferases," Proceedings of the National Academy of Sciences of the United States of America, vol. 102, no. 5, pp. 1548-1553, 2005.

[7] G. J. Quellhorst Jr., J. S. Piotrowski, S. E. Steffen, and S. S. Krag, "Identification of Schizosaccharomyces pombe prenol as dolichol-16,17," Biochemical and Biophysical Research Communications, vol. 244, no. 2, pp. 546-550, 1998.

[8] J. W. Rip, C. A. Rupar, K. Ravi, and K. K. Carroll, "Distribution, metabolism and function of dolichol and polyprenols," Progress in Lipid Research, vol. 24, no. 4, pp. 269-309, 1985.

[9] J. S. Rush, N. Gao, M. A. Lehrman, S. Matveev, and C. J. Waechter, "Suppression of Rftl expression does not impair the transbilayer movement of $\mathrm{Man}_{5} \mathrm{GlcNAc}_{2}$-P-P-dolichol in sealed microsomes from yeast," Journal of Biological Chemistry, vol. 284, no. 30, pp. 19835-19842, 2009.

[10] M. A. Haeuptle, F. M. Pujol, C. Neupert et al., "Human RFT1 deficiency leads to a disorder of N-linked glycosylation," The American Journal of Human Genetics, vol. 82, no. 3, pp. 600606, 2008.

[11] J. Jelk, N. Gao, M. Serricchio et al., "Glycoprotein biosynthesis in a eukaryote lacking the membrane protein Rft1," Journal of Biological Chemistry, vol. 288, no. 28, pp. 20616-20623, 2013.

[12] R. Kornfeld and S. Kornfeld, "Assembly of asparagine-linked oligosaccharides," Annual Review of Biochemistry, vol. 54, pp. 631-664, 1985.

[13] D. Karaoglu, D. J. Kelleher, and R. Gilmore, "The highly conserved Stt3 protein is a subunit of the yeast oligosaccharyltransferase and forms a subcomplex with Ost3p and Ost4p," The Journal of Biological Chemistry, vol. 272, no. 51, pp. 32513-32520, 1997.

[14] D. J. Kelleher and R. Gilmore, "DAD1: the defender against apoptotic cell death, is a subunit of the mammalian oligosaccharyltransferase," Proceedings of the National Academy of Sciences of the United States of America, vol. 94, no. 10, pp. 4994-4999, 1997.

[15] D. J. Kelleher, D. Karaoglu, E. C. Mandon, and R. Gilmore, "Oligosaccharyltransferase isoforms that contain different catalytic STT3 subunits have distinct enzymatic properties," Molecular Cell, vol. 12, no. 1, pp. 101-111, 2003.

[16] T. Shibatani, L. L. David, A. L. McCormack, K. Frueh, and W. R. Skach, "Proteomic analysis of mammalian oligosaccharyltransferase reveals multiple subcomplexes that contain Sec61, TRAP, and two potential new subunits," Biochemistry, vol. 44, no. 16, pp. 5982-5992, 2005.

[17] K. McBride, C. Baron, S. Picard et al., "The model B6dom1 minor histocompatibility antigen is encoded by a mouse homolog of the yeast STT3 gene," Immunogenetics, vol. 54, no. 8, pp. 562-569, 2002.

[18] G. Hong, W. Deleersnijder, C. A. Kozak, E. van Marck, P. Tylzanowski, and J. Merregaert, "Molecular cloning of a highly conserved mouse and human integral membrane protein (ltml) and genetic mapping to mouse chromosome 9," Genomics, vol. 31, no. 3, pp. 295-300, 1996.

[19] C. Ruiz-Canada, D. J. Kelleher, and R. Gilmore, "Cotranslational and posttranslational N-glycosylation of polypeptides by distinct mammalian OST isoforms," Cell, vol. 136, no. 2, pp. 272283, 2009.

[20] P. Roboti and S. High, "Keratinocyte-associated protein 2 is a bona fide subunit of the mammalian oligosaccharyltransferase," Journal of Cell Science, vol. 125, no. 1, pp. 220-232, 2012.

[21] H. M. Mora-Montes, S. Bates, M. G. Netea et al., "Endoplasmic reticulum alpha-glycosidases of Candida albicans are required for $N$-glycosylation, cell wall integrity, and normal host-fungus interaction," Eukaryotic Cell, vol. 6, no. 12, pp. 2184-2193, 2007.

[22] A. B. Herrero, P. Magnelli, M. K. Mansour, S. M. Levitz, H. Bussey, and C. Abeijon, "KRE5 gene null mutant strains of Candida albicans are avirulent and have altered cell wall composition and hypha formation properties," Eukaryotic Cell, vol. 3, no. 6, pp. 1423-1432, 2004.

[23] L. Ellgaard and A. Helenius, "Quality control in the endoplasmic reticulum," Nature Reviews Molecular Cell Biology, vol. 4, no. 3, pp. 181-191, 2003.

[24] D. Chui, M. Oh-Eda, Y. Liao et al., "Alpha-mannosidase-II deficiency results in dyserythropoiesis and unveils an alternate pathway in oligosaccharide biosynthesis," Cell, vol. 90, no. 1, pp. 157-167, 1997.

[25] M. Oh-Eda, H. Nakagawa, T. O. Akama et al., "Overexpression of the Golgi-localized enzyme $\alpha$-mannosidase IIx in Chinese hamster ovary cells results in the conversion of hexamannosyl$\mathrm{N}$-acetylchitobiose to tetramannosyl-N-acetylchitobiose in the $\mathrm{N}$-glycan-processing pathway," European Journal of Biochemistry, vol. 268, no. 5, pp. 1280-1288, 2001.

[26] M. N. Fukuda and T. O. Akama, "In vivo role of $\alpha$-mannosidase IIx: ineffective spermatogenesis resulting from targeted disruption of the Man2a2 in the mouse," Biochimica et Biophysica Acta-General Subjects, vol. 1573, no. 3, pp. 382-387, 2002.

[27] A. Varki, Essentials of Glycobiology, Cold Spring Harbor Laboratory Press, New York, NY, USA, 2nd edition, 2009.

[28] H. J. Gabius and S. Gabius, Glycosciences: Status and Perspectives, John Wiley \& Sons, 2002.

[29] A. Varki, "Glycan-based interactions involving vertebrate sialicacid-recognizing proteins," Nature, vol. 446, no. 7139, pp. 1023 1029, 2007.

[30] A. Harduin-Lepers, R. Mollicone, P. Delannoy, and R. Oriol, "The animal sialyltransferases and sialyltransferase-related genes: a phylogenetic approach," Glycobiology, vol. 15, no. 8, pp. 805-817, 2005.

[31] R. Schauer, "Biosynthesis and function of N- and O-substituted sialic acids," Glycobiology, vol. 1, no. 5, pp. 449-452, 1991.

[32] N. M. Varki and A. Varki, "Diversity in cell surface sialic acid presentations: implications for biology and disease," Laboratory Investigation, vol. 87, no. 9, pp. 851-857, 2007. 
[33] J. L. López-Ribot, J. P. Martínez, C. Monteagudo, H. M. Alloush, N. V. Mattioli, and W. L. Chaffin, "Evidence for the presence of complex carbohydrates in Candida albicans cell wall glycoproteins," Revista Iberoamericana de Micologia, vol. 16, no. 1, pp. 23-26, 1999.

[34] R. M. Soares, R. M. de A. Soares, D. S. Alviano, J. Angluster, C. S. Alviano, and L. R. Travassos, "Identification of sialic acids on the cell surface of Candida albicans," Biochimica et Biophysica Acta, vol. 1474, no. 2, pp. 262-268, 2000.

[35] J. Masuoka, "Surface glycans of Candida albicans and other pathogenic fungi: physiological roles, clinical uses, and experimental challenges," Clinical Microbiology Reviews, vol. 17, no. 2, pp. 281-310, 2004.

[36] J. A. Wasylnka, M. I. Simmer, and M. M. Moore, "Differences in sialic acid density in pathogenic and non-pathogenic Aspergillus species," Microbiology, vol. 147, part 4, pp. 869-877, 2001.

[37] M. L. Rodrigues, A. S. S. Dobroff, J. N. D. S. S. Couceiro, C. S. Alviano, R. Schauer, and L. R. Travassos, "Sialylglycoconjugates and sialyltransferase activity in the fungus Cryptococcus neoformans," Glycoconjugate Journal, vol. 19, no. 3, pp. 165-173, 2003.

[38] R. Oriol, R. Mollicone, A. Cailleau, L. Balanzino, and C. Breton, "Divergent evolution of fucosyltransferase genes from vertebrates, invertebrates, and bacteria," Glycobiology, vol. 9, no. 4, pp. 323-334, 1999.

[39] R. G. Lima-Neto, E. I. C. Beltrão, P. C. Oliveira, and R. P. Neves, "Adherence of Candida albicans and Candida parapsilosis to epithelial cells correlates with fungal cell surface carbohydrates," Mycoses, vol. 54, no. 1, pp. 23-29, 2011.

[40] J. Grass, M. Pabst, D. Kolarich et al., "Discovery and structural characterization of fucosylated oligomannosidic $N$-glycans in mushrooms," The Journal of Biological Chemistry, vol. 286, no. 8, pp. 5977-5984, 2011.

[41] M. F. Coutinho, M. J. Prata, and S. Alves, "Mannose-6phosphate pathway: a review on its role in lysosomal function and dysfunction," Molecular Genetics and Metabolism, vol. 105, no. 4, pp. 542-550, 2012.

[42] W. Lee, B. J. Payne, C. M. Gelfman, P. Vogel, and S. Kornfeld, "Murine UDP-GlcNAc:Lysosomal enzyme N-acetylglucosamine-1-phosphotransferase lacking the $\gamma$-subunit retains substantial activity toward acid hydrolases," Journal of Biological Chemistry, vol. 282, no. 37, pp. 27198-27203, 2007.

[43] J. R. C. Whyte and S. Munro, "A yeast homolog of the mammalian mannose 6-phosphate receptors contributes to the sorting of vacuolar hydrolases," Current Biology, vol. 11, no. 13, pp. 1074-1078, 2001.

[44] S. Bates, H. B. Hughes, C. A. Munro et al., "Outer chain Nglycans are required for cell wall integrity and virulence of Candida albicans," The Journal of Biological Chemistry, vol. 281, no. 1, pp. 90-98, 2006.

[45] D. Rodionov, P. A. Romero, A. M. Berghuis, and A. Herscovics, "Expression and purification of recombinant M-Pol I from Saccharomyces cerevisiae with alpha-1,6 mannosylpolymerase activity," Protein Expression and Purification, vol. 66, no. 1, pp. $1-6,2009$.

[46] J. Jungmann and S. Munro, "Multi-protein complexes in the cis Golgi of Saccharomyces cerevisiae with $\alpha$-1,6mannosyltransferase activity," The EMBO Journal, vol. 17, no. 2, pp. 423-434, 1998.
[47] J. Jungmann, J. C. Rayner, and S. Munro, "The Saccharomyces cerevisiae protein Mnn10p/Bedlp is a subunit of a Golgi mannosyltransferase complex," The Journal of Biological Chemistry, vol. 274, no. 10, pp. 6579-6585, 1999.

[48] S. B. Southard, C. A. Specht, C. Mishra, J. Chen-Weiner, and P. W. Robbins, "Molecular analysis of the Candida albicans homolog of Saccharomyces cerevisiae MNN9, required for glycosylation of cell wall mannoproteins," Journal of Bacteriology, vol. 181, no. 24, pp. 7439-7448, 1999.

[49] J. C. Rayner and S. Munro, "Identification of the MNN2 and MNN5 mannosyltransferases required for forming and extending the mannose branches of the outer chain mannans of Saccharomyces cerevisiae," Journal of Biological Chemistry, vol. 273, no. 41, pp. 26836-26843, 1998.

[50] C. Bai, X. Xu, F. Chan, R. T. H. Lee, and Y. Wang, "MNN5 encodes an iron-regulated $\alpha$-1,2-mannosyltransferase important for protein glycosylation, cell wall integrity, morphogenesis, and virulence in Candida albicans," Eukaryotic Cell, vol. 5, no. 2, pp. 238-247, 2006.

[51] H. M. Mora-Montes, S. Bates, M. G. Netea et al., "A multifunctional mannosyltransferase family in candida albicans determines cell wall mannan structure and host-fungus interactions," Journal of Biological Chemistry, vol. 285, no. 16, pp. 12087-12095, 2010.

[52] R. A. Hall, S. Bates, M. D. Lenardon et al., "The Mnn2 mannosyltransferase family modulates mannoprotein fibril length, immune recognition and virulence of Candida albicans," PLoS Pathogens, vol. 9, no. 4, Article ID e1003276, 2013.

[53] M. Lussier, A. Sdicu, and H. Bussey, "The KTR and MNN1 mannosyltransferase families of Saccharomyces cerevisiae," Biochimica et Biophysica Acta, vol. 1426, no. 2, pp. 323-334, 1999.

[54] S. Bates, R. A. Hall, J. Cheetham et al., "Role of the Candida albicans MNN1 gene family in cell wall structure and virulence," BMC Research Notes, vol. 6, no. 1, article 294, 2013.

[55] N. Shibata, M. Arai, E. Haga et al., "Structural identification of an epitope of antigenic factor 5 in mannans of Candida albicans NIH B-792 (serotype B) and J-1012 (serotype A) as $\beta$-1,2- linked oligomannosyl residues," Infection and Immunity, vol. 60, no. 10, pp. 4100-4110, 1992.

[56] C. Mille, P. Bobrowicz, P. Trinel et al., "Identification of a new family of genes involved in $\beta-1,2$ - mannosylation of glycans in Pichia pastoris and Candida albicans," Journal of Biological Chemistry, vol. 283, no. 15, pp. 9724-9736, 2008.

[57] R. P. Hobson, C. A. Munro, S. Bates et al., "Loss of cell wall mannosylphosphate in Candida albicans does not influence macrophage recognition," Journal of Biological Chemistry, vol. 279, no. 38, pp. 39628-39635, 2004.

[58] G. Butler, M. D. Rasmussen, M. F. Lin et al., "Evolution of pathogenicity and sexual reproduction in eight Candida genomes," Nature, vol. 459, no. 7247, pp. 657-662, 2009.

[59] P. A. Trinel, G. Lepage, T. Jouault, G. Strecker, and D. Poulain, "Definitive chemical evidence for the constitutive ability of Candida albicans serotype A strains to synthesize $\beta-1,2$ linked oligomannosides containing up to 14 mannose residues," FEBS Letters, vol. 416, no. 2, pp. 203-206, 1997.

[60] M. Aebi, R. Bernasconi, S. Clerc, and M. Molinari, "N-glycan structures: recognition and processing in the ER," Trends in Biochemical Sciences, vol. 35, no. 2, pp. 74-82, 2010.

[61] J. Jaeken, "Congenital disorders of glycosylation (CDG): it's (nearly) all in it!", Journal of Inherited Metabolic Disease, vol. 34, no. 4, pp. 853-858, 2011. 
[62] W. L. Chaffin, "Effect of tunicamycin on germ tube and yeast bud formation in Candida albicans," Journal of General Microbiology, vol. 131, no. 8, pp. 1853-1861, 1985.

[63] S. Bates, D. M. MacCallum, G. Bertram et al., "Candida albicans Pmrlp, a secretory pathway P-type $\mathrm{Ca}^{2+} / \mathrm{Mn}^{2+}$-ATPase, is required for glycosylation and virulence," The Journal of Biological Chemistry, vol. 280, no. 24, pp. 23408-23415, 2005.

[64] C. G. Pierce, D. P. Thomas, and J. L. López-Ribot, "Effect of tunicamycin on Candida albicans biofilm formation and maintenance," Journal of Antimicrobial Chemotherapy, vol. 63, no. 3, pp. 473-479, 2009.

[65] R.-K. Li and J. E. Cutler, "Chemical definition of an epitope/adhesin molecule on Candida albicans," The Journal of Biological Chemistry, vol. 268, no. 24, pp. 18293-18299, 1993.

[66] P. Sundstrom, "Adhesins in Candida albicans," Current Opinion in Microbiology, vol. 2, no. 4, pp. 353-357, 1999.

[67] L. L. Hoyer, "The ALS gene family of Candida albicans," Trends in Microbiology, vol. 9, no. 4, pp. 176-180, 2001.

[68] P. Sundstrom, "Adhesion in Candida spp," Cellular Microbiology, vol. 4, no. 8, pp. 461-469, 2002.

[69] D. Poulain and T. Jouault, "Candida albicans cell wall glycans, host receptors and responses: elements for a decisive crosstalk," Current Opinion in Microbiology, vol. 7, no. 4, pp. 342-349, 2004.

[70] J. Finne, T. Krusius, R. K. Margolis, and R. U. Margolis, "Novel mannitol-containing oligosaccharides obtained by mild alkaline borohydride treatment of a chondroitin sulfate proteoglycan from brain., Journal of Biological Chemistry, vol. 254, no. 20, pp. 10295-10300, 1979.

[71] C. A. Munro, S. Bates, E. T. Buurman et al., "Mntlp and Mnt2p of Candida albicans are partially redundant alpha-1,2mannosyltransferases that participate in O-linked mannosylation and are required for adhesion and virulence," Journal of Biological Chemistry, vol. 280, no. 2, pp. 1051-1060, 2005.

[72] W. Chai, C. Yuen, H. Kogelberg et al., "High prevalence of 2mono- and 2,6-di-substituted manol-terminating sequences among $\mathrm{O}$-glycans released from brain glycopeptides by reductive alkaline hydrolysis," European Journal of Biochemistry, vol. 263, no. 3, pp. 879-888, 1999.

[73] L. A. Jurado, A. Coloma, and J. Cruces, "Identification of a human homolog of the Drosophila rotated abdomen gene (POMT1) encoding a putative protein O-mannosyl-transferase, and assignment to human chromosome 9q34.1," Genomics, vol. 58, no. 2, pp. 171-180, 1999.

[74] T. Willer, W. Amselgruber, R. Deutzmann, and S. Strahl, "Characterization of POMT2, a novel member of the PMT protein O-mannosyltransferase family specifically localized to the acrosome of mammalian spermatids," Glycobiology, vol. 12, no. 11, pp. 771-783, 2002.

[75] K. Akasaka-Manya, H. Manya, A. Nakajima, M. Kawakita, and T. Endo, "Physical and functional association of human protein O-mannosyltransferases 1 and 2," Journal of Biological Chemistry, vol. 281, no. 28, pp. 19339-19345, 2006.

[76] S. Takahashi, T. Sasaki, H. Manya et al., "A new $\beta-1,2-N-$ acetylglucosaminyltransferase that may play a role in the biosynthesis of mammalian O-mannosyl glycans," Glycobiology, vol. 11, no. 1, pp. 37-45, 2001.

[77] T. Yoshida-Moriguchi, L. Yu, S. Stalnaker et al., “O-Mannosyl phosphorylation of alpha-dystroglycan is required for laminin binding," Science, vol. 327, no. 5961, pp. 88-92, 2010.
[78] T. Yoshida-Moriguchi, T. Willer, M. E. Anderson et al., "SGK196 is a glycosylation-specific O-mannose kinase required for dystroglycan function," Science, vol. 341, no. 6148, pp. 896-899, 2013.

[79] J. E. Hewitt, "LARGE enzyme activity deciphered: a new therapeutic target for muscular dystrophies," Genome Medicine, vol. 4, no. 3, article 23, 2012.

[80] K. Inamori, Y. Hara, T. Willer et al., "Xylosyl- and glucuronyltransferase functions of LARGE in $\alpha$-dystroglycan modification are conserved in LARGE2," Glycobiology, vol. 23, no. 3, pp. 295302, 2013.

[81] S. K. Prill, B. Klinkert, C. Timpel, C. A. Gale, K. Schröppel, and J. F. Ernst, "PMT family of Candida albicans: Five protein mannosyltransferase isoforms affect growth, morphogenesis and antifungal resistance," Molecular Microbiology, vol. 55, no. 2, pp. 546-560, 2005.

[82] K. B. Lengeler, D. Tielker, and J. F. Ernst, "Protein-Omannosyltransferases in virulence and development," Cellular and Molecular Life Sciences, vol. 65, no. 4, pp. 528-544, 2008.

[83] P. D. Cantero, C. Lengsfeld, S. K.-. Prill et al., “Transcriptional and physiological adaptation to defective protein-Omannosylation in Candida albicans," Molecular Microbiology, vol. 64, no. 4, pp. 1115-1128, 2007.

[84] V. Girrbach and S. Strahl, "Members of the evolutionarily conserved PMT family of protein $O$-mannosyltransferases form distinct protein complexes among themselves," The Journal of Biological Chemistry, vol. 278, no. 14, pp. 12554-12562, 2003.

[85] D. F. Díaz-Jiménez, H. M. Mora-Montes, A. HernándezCervantes, J. P. Luna-Arias, N. A. R. Gow, and A. FloresCarreón, "Biochemical characterization of recombinant Candida albicans mannosyltransferases Mnt1, Mnt2 and Mnt5 reveals new functions in O- and N-mannan biosynthesis," Biochemical and Biophysical Research Communications, vol. 419, no. 1, pp. 77-82, 2012.

[86] T. Endo, "Dystroglycan glycosylation and its role in $\alpha$ dystroglycanopathies," Acta Myologica, vol. 26, no. 3, pp. 165170, 2007.

[87] C. Godfrey, A. R. Foley, E. Clement, and F. Muntoni, "Dystroglycanopathies: coming into focus," Current Opinion in Genetics and Development, vol. 21, no. 3, pp. 278-285, 2011.

[88] M. G. Netea, N. A. R. Gow, C. A. Munro et al., "Immune sensing of Candida albicans requires cooperative recognition of mannans and glucans by lectin and Toll-like receptors," Journal of Clinical Investigation, vol. 116, no. 6, pp. 1642-1650, 2006.

[89] M. Rouabhia, M. Schaller, C. Corbucci et al., "Virulence of the fungal pathogen Candida albicans requires the five isoforms of protein mannosyltransferases," Infection and Immunity, vol. 73, no. 8, pp. 4571-4580, 2005.

[90] C. Timpel, S. Zink, S. Strahl-Bolsinger, K. Schröppel, and J. Ernst, "Morphogenesis, adhesive properties, and antifungal resistance depend on the Pmt6 protein mannosyltransferase in the fungal pathogen Candida albicans," Journal of Bacteriology, vol. 182, no. 11, pp. 3063-3071, 2000.

[91] H. Peltroche-Llacsahuanga, S. Goyard, C. D’Enfert, S. K. Prill, and J. F. Ernst, "Protein O-mannosyltransferase isoforms regulate biofilm formation in Candida albicans," Antimicrobial Agents and Chemotherapy, vol. 50, no. 10, pp. 3488-3491, 2006.

[92] C. Murciano, D. L. Moyes, M. Runglall et al., "Candida albicans cell wall glycosylation may be indirectly required for activation of epithelial cell proinflammatory responses," Infection and Immunity, vol. 79, no. 12, pp. 4902-4911, 2011. 
[93] C. C. Sheth, R. Hall, L. Lewis et al., "Glycosylation status of the C. albicans cell wall affects the efficiency of neutrophil phagocytosis and killing but not cytokine signaling," Medical Mycology, vol. 49, no. 5, pp. 513-524, 2011.

[94] M. G. Netea, C. A. A. Van der Graaf, A. G. Vonk, I. Verschueren, J. W. M. Van der Meet, and B. J. Kullberg, "The role of tolllike receptor (TLR) 2 and TLR4 in the host defense against disseminated candidiasis," Journal of Infectious Diseases, vol. 185, no. 10, pp. 1483-1489, 2002.

[95] T. H. Gasparoto, V. Tessarolli, T. P. Garlet et al., "Absence of functional TLR4 impairs response of macrophages after Candida albicans infection," Medical Mycology, vol. 48, no. 8, pp. 1009-1017, 2010.

[96] G. Ferwerda, F. Meyer-Wentrup, B. Kullberg, M. G. Netea, and G. J. Adema, "Dectin-1 synergizes with TLR2 and TLR4 for cytokine production in human primary monocytes and macrophages," Cellular Microbiology, vol. 10, no. 10, pp. 20582066, 2008.

[97] K. M. Dennehy, G. Ferwerda, I. Faro-Trindade et al., "Syk kinase is required for collaborative cytokine production induced through Dectin-1 and Toll-like receptors," European Journal of Immunology, vol. 38, no. 2, pp. 500-506, 2008.

[98] A. Cambi, M. G. Netea, H. M. Mora-Montes et al., "Dendritic cell interaction with Candida albicans critically depends on $\mathrm{N}$ linked Mannan," Journal of Biological Chemistry, vol. 283, no. 29, pp. 20590-20599, 2008.

[99] M. G. Netea, N. A. R. Gow, L. A. B. Joosten, I. Verschueren, J. W. M. Van Der Meer, and B. J. Kullberg, "Variable recognition of Candida albicans strains by TLR4 and lectin recognition receptors," Medical Mycology, vol. 48, no. 7, pp. 897-903, 2010.

[100] R. Watanabe, N. Inoue, B. Westfall et al., "The first step of glycosylphosphatidylinositol biosynthesis is mediated by a complex of PIG-A, PIG-H, PIG-C and GPI1," EMBO Journal, vol. 17, no. 4, pp. 877-885, 1998.

[101] S. D. Leidich, Z. Kostova, R. R. Latek et al., “Temperaturesensitive yeast GPI anchoring mutants gpi2 and gpi3 are defective in the synthesis of $\mathrm{N}$-acetylglucosaminyl phosphatidylinositol: cloning of the GPI2 gene," Journal of Biological Chemistry, vol. 270, no. 22, pp. 13029-13035, 1995.

[102] N. Inoue, R. Watanabe, J. Takeda, and T. Kinoshita, "PIG-C, one of the three human genes involved in the first step of glycosylphosphatidylinositol biosynthesis is a homologue of Saccharomyces cerevisiae GPI2," Biochemical and Biophysical Research Communications, vol. 226, no. 1, pp. 193-199, 1996.

[103] B. C. Yan, B. A. Westfall, and P. Orlean, "Ynl038wp (Gpil5p) is the Saccharomyces cerevisiae homologue of human Pig-Hp and participates in the first step in glycosylphosphatidylinositol assembly," Yeast, vol. 18, no. 15, pp. 1383-1389, 2001.

[104] H. A. Newman, M. J. Romeo, S. E. Lewis, B. C. Yan, P. Orlean, and D. E. Levin, "Gpi19: the Saccharomyces cerevisiae homologue of mammalian PIG-P, is a subunit of the initial enzyme for glycosylphosphatidylinositol anchor biosynthesis," Eukaryotic Cell, vol. 4, no. 11, pp. 1801-1807, 2005.

[105] S. D. Leidich and P. Orlean, "Gpil, a Saccharomyces cerevisiae protein that participates in the first step in glycosylphosphatidylinositol anchor synthesis," The Journal of Biological Chemistry, vol. 271, no. 44, pp. 27829-27837, 1996.

[106] A. Tiede, C. Nischan, J. Schubert, and R. E. Schmidt, "Characterisation of the enzymatic complex for the first step in glycosylphosphatidylinositol biosynthesis," International Journal of Biochemistry and Cell Biology, vol. 32, no. 3, pp. 339-350, 2000.
[107] Y. Murakami, U. Siripanyaphinyo, Y. Hong, Y. Tashima, Y. Maeda, and T. Kinoshita, "The initial enzyme for glycosylphosphatidylinositol biosynthesis requires PIG-Y, a seventh component," Molecular Biology of the Cell, vol. 16, no. 11, pp. 5236-5246, 2005.

[108] R. Watanabe, K. Ohishi, Y. Maeda, N. Nakamura, and T. Kinoshita, "Mammalian PIG-L and its yeast homologue Gpi12p are $\mathrm{N}$-acetylglucosaminylphosphatidylinositol de-N-acetylases essential in glycosylphosphatidylinositol biosynthesis," Biochemical Journal, vol. 339, no. 1, pp. 185-192, 1999.

[109] Y. Murakami, U. Siripanyapinyo, Y. Hong et al., "PIG-W is critical for inositol acylation but not for flipping of glycosylphosphatidylinositol-anchor," Molecular Biology of the Cell, vol. 14, no. 10, pp. 4285-4295, 2003.

[110] M. Umemura, M. Okamoto, K. Nakayama et al., "GWT1 gene is required for inositol acylation of glycosylphosphatidylinositol anchors in yeast," Journal of Biological Chemistry, vol. 278, no. 26, pp. 23639-23647, 2003.

[111] Y. Maeda, R. Watanabe, C. L. Harris et al., "PIG-M transfers the first mannose to glycosylphosphatidylinositol on the lumenal side of the ER," EMBO Journal, vol. 20, no. 1-2, pp. 250-261, 2001.

[112] J. Y. Kang, H. Yeongjin, H. Ashida et al., "PIG-V involved in transferring the second mannose in glycosylphosphatidylinositol," Journal of Biological Chemistry, vol. 280, no. 10, pp. 94899497, 2005.

[113] A. Fabre, P. Orlean, and C. H. Taron, "Saccharomyces cerevisiae $\mathrm{Ybr} 004 \mathrm{c}$ and its human homologue are required for addition of the second mannose during glycosylphosphatidylinositol precursor assembly," FEBS Journal, vol. 272, no. 5, pp. 1160-1168, 2005.

[114] M. Takahashi, N. Inoue, K. Ohishi et al., "PIG-B: a membrane protein of the endoplasmic reticulum with a large lumenal domain, is involved in transferring the third mannose of the GPI anchor," The EMBO Journal, vol. 15, no. 16, pp. 4254-4261, 1996.

[115] C. Sütterlin, M. V. Escribano, P. Gerold et al., "Saccharomyces cerevisiae GPI10, the functional homologue of human PIG-B, is required for glycosylphosphatidylinositol-anchor synthesis," Biochemical Journal, vol. 332, no. 1, pp. 153-159, 1998.

[116] S. J. Grimme, B. A. Westfall, J. M. Wiedman, C. H. Taron, and P. Orlean, "The essential Smp3 protein is required for addition of the side-branching fourth mannose during assembly of yeast glycosylphosphatidylinositols," Journal of Biological Chemistry, vol. 276, no. 29, pp. 27731-27739, 2001.

[117] B. W. Taron, P. A. Colussi, J. M. Wiedman, P. Orlean, and C. H. Taron, "Human Smp3p adds a fourth mannose to yeast and human glycosylphosphatidylinositol precursors in vivo," The Journal of Biological Chemistry, vol. 279, no. 34, pp. 3608336092, 2004.

[118] S. J. Grimme, P. A. Colussi, C. H. Taron, and P. Orlean, "Deficiencies in the essential Smp3 mannosyl-transferase block glycosylphosphatidylinositol assembly and lead to defects in growth and cell wall biogenesis in Candida albicans," Microbiology, vol. 150, part 10, pp. 3115-3128, 2004.

[119] Y. Hong, Y. Maeda, R. Watanabe et al., "Pig-n, a mammalian homologue of yeast Mcd4p, is involved in transferring phosphoethanolamine to the first mannose of the glycosylphosphatidylinositol," Journal of Biological Chemistry, vol. 274, no. 49, pp. 35099-35106, 1999.

[120] A. Benachour, G. Sipos, I. Flury et al., "Deletion of GPI7, a yeast gene required for addition of a side chain to the glycosylphosphatidylinositol (GPI) core structure, affects GPI 
protein transport, remodeling, and cell wall integrity," Journal of Biological Chemistry, vol. 274, no. 21, pp. 15251-15261, 1999.

[121] N. Shishioh, Y. Hong, K. Ohishi, H. Ashida, Y. Maeda, and T. Kinoshita, "GPI7 is the second partner of PIG-F and involved in modification of glycosylphosphatidylinositol," Journal of Biological Chemistry, vol. 280, no. 10, pp. 9728-9734, 2005.

[122] C. H. Taron, J. M. Wiedman, S. J. Grimme, and P. Orlean, "Glycosylphosphatidylinositol biosynthesis defects in Gpillpand Gpil3p- deficient yeast suggest a branched pathway and implicate Gpil3p in phosphoethanolamine transfer to the third mannose," Molecular Biology of the Cell, vol. 11, no. 5, pp. 16111630, 2000.

[123] Y. Hong, Y. Maeda, R. Watanabe, N. Inoue, K. Ohishi, and T. Kinoshita, "Requirement of PIG-F and PIG-O for transferring phosphoethanolamine to the third mannose in glycosylphosphatidylinositol," The Journal of Biological Chemistry, vol. 275, no. 27, pp. 20911-20919, 2000.

[124] P. Orlean and A. K. Menon, "Thematic review series: lipid posttranslational modifications. GPI anchoring of protein in yeast and mammalian cells, or: how we learned to stop worrying and love glycophospholipids," Journal of Lipid Research, vol. 48, no. 5, pp. 993-1011, 2007.

[125] D. Hamburger, M. Egerton, and H. Riezman, "Yeast Gaalp is required for attachment of a completed GPI anchor onto proteins," Journal of Cell Biology, vol. 129, no. 3, pp. 629-639, 1995.

[126] Y. Hong, K. Ohishi, J. Y. Kang et al., "Human PIG-U and yeast Cdc91p are the fifth subunit of GPI transamidase that attaches GPI-anchors to proteins," Molecular Biology of the Cell, vol. 14, no. 5, pp. 1780-1789, 2003.

[127] S. Tanaka, Y. Maeda, Y. Tashima, and T. Kinoshita, "Inositol Deacylation of Glycosylphosphatidylinositol-anchored Proteins Is Mediated by Mammalian PGAP1 and Yeast Bstlp," Journal of Biological Chemistry, vol. 279, no. 14, pp. 14256-14263, 2004.

[128] M. Fujita, M. Umemura, T. Yoko-O, and Y. Jigami, "PER1 is required for GPI-phospholipase A2 activity and involved in lipid remodeling of GPI-anchored proteins," Molecular Biology of the Cell, vol. 17, no. 12, pp. 5253-5264, 2006.

[129] Y. Maeda, Y. Tashima, T. Houjou et al., "Fatty acid remodeling of GPI-anchored proteins is required for their raft association," Molecular Biology of the Cell, vol. 18, no. 4, pp. 1497-1506, 2007.

[130] R. Bosson, M. Jaquenoud, and A. Conzelmann, "GUP1 of Saccharomyces cerevisiae encodes an $O$-acyltransferase involved in remodeling of the GPI anchor," Molecular Biology of the Cell, vol. 17, no. 6, pp. 2636-2645, 2006.

[131] Y. Tashima, R. Taguchi, C. Murata, H. Ashida, T. Kinoshita, and Y. Maeda, "PGAP2 is essential for correct processing and stable expression of GPI-anchored proteins," Molecular Biology of the Cell, vol. 17, no. 3, pp. 1410-1420, 2006.

[132] P. Pramoonjago, W. Wanachiwanawin, S. Chinprasertsuk, K. Pattanapanyasat, J. Takeda, and T. Kinoshita, "PIG-A gene abnormalities in Thai patients with paroxysmal nocturnal hemoglobinuria," The Southeast Asian Journal of Tropical Medicine and Public Health, vol. 26, supplement 1, pp. 322-324, 1995.

[133] A. M. Almeida, Y. Murakami, D. M. Layton et al., "Hypomorphic promoter mutation in PIGM causes inherited glycosylphosphatidylinositol deficiency," Nature Medicine, vol. 12, no. 7, pp. 846-851, 2006.
[134] H. H. Freeze, J. X. Chong, M. J. Bamshad, and B. G. Ng, "Solving glycosylation disorders: fundamental approaches reveal complicated pathways," The American Journal of Human Genetics, vol. 94, no. 2, pp. 161-175, 2014.

[135] S. D. Leidich, D. A. Drapp, and P. Orlean, "A conditionally lethal yeast mutant blocked at the first step in glycosyl phosphatidylinositol anchor synthesis," Journal of Biological Chemistry, vol. 269, no. 14, pp. 10193-10196, 1994.

[136] A. Plaine, L. Walker, G. Da Costa et al., "Functional analysis of Candida albicans GPI-anchored proteins: roles in cell wall integrity and caspofungin sensitivity," Fungal Genetics and Biology, vol. 45, no. 10, pp. 1404-1414, 2008.

[137] M. Richard, P. de Groot, O. Courtin, D. Poulain, F. Klis, and C. Gaillardin, "GP17 affects cell-wall protein anchorage in Saccharomyces cerevisiae and Candida albicans," Microbiology, vol. 148, part 7, pp. 2125-2133, 2002.

[138] G. S. Victoria, P. Kumar, and S. S. Komath, "The Candida albicans homologue of PIG-P, CaGpi19p: gene dosage and role in growth and filamentation," Microbiology, vol. 156, no. 10, pp. 3041-3051, 2010.

[139] B. Yadav, S. Bhatnagar, M. F. Ahmad et al., "First step of glycosylphosphatidylinositol (GPI) biosynthesis cross-talks with ergosterol biosynthesis and Ras signaling in Candida albicans," The Journal of Biological Chemistry, vol. 289, no. 6, pp. 33653382, 2014.

[140] D. C. Sheppard, M. R. Yeaman, W. H. Welch et al., "Functional and structural diversity in the Als protein family of Candida albicans," The Journal of Biological Chemistry, vol. 279, no. 29, pp. 30480-30489, 2004.

[141] G. Patsos, V. Hebbe-Viton, R. San Martin, C. Paraskeva, T. Gallagher, and A. Corfield, "Action of a library of O-glycosylation inhibitors on the growth of human colorectal cancer cells in culture," Biochemical Society Transactions, vol. 33, no. 4, pp. 721723, 2005.

[142] B. S. Dwarakanath, "Cytotoxicity, radiosensitization, and chemosensitization of tumor cells by 2-deoxy-D-glucose in vitro.", Journal of cancer research and therapeutics, vol. 5, supplement 1, pp. S27-S31, 2009.

[143] D. Díaz-Jiménez, L. A. Pérez-García, J. A. Martínez-Álvarez, and H. M. Mora-Montes, "Role of the fungal cell wall in pathogenesis and antifungal resistance," Current Fungal Infection Reports, vol. 6, no. 4, pp. 275-282, 2012.

[144] N. P. J. Price and B. Tsvetanova, "Biosynthesis of the tunicamycins: a review," Journal of Antibiotics, vol. 60, no. 8, pp. 485491, 2007.

[145] S. P. Lim, Q. Y. Wang, C. G. Noble et al., "Ten years of dengue drug discovery: progress and prospects," Antiviral Research, vol. 100, no. 2, pp. 500-519, 2013.

[146] J. Chang, T. M. Block, and J. T. Guo, "Antiviral therapies targeting host ER alpha-glucosidases: current status and future directions," Antiviral Research, vol. 99, no. 3, pp. 251-260, 2013.

[147] J. Chang, T. K. Warren, X. Zhao et al., "Small molecule inhibitors of ER $\alpha$-glucosidases are active against multiple hemorrhagic fever viruses," Antiviral Research, vol. 98, no. 3, pp. 432-440, 2013.

[148] J. D. Howe, N. Smith, M. J. Lee et al., "Novel imino sugar alphaglucosidase inhibitors as antiviral compounds," Bioorganic and Medicinal Chemistry, vol. 21, no. 16, pp. 4831-4838, 2013.

[149] X. Qu, X. Pan, J. Weidner et al., "Inhibitors of endoplasmic reticulum $\alpha$-glucosidases potently suppress hepatitis $C$ virus virion assembly and release," Antimicrobial Agents and Chemotherapy, vol. 55, no. 3, pp. 1036-1044, 2011. 
[150] D. Durantel, "Celgosivir, an $\alpha$-glucosidase I inhibitor for the potential treatment of HCV infection," Current Opinion in Investigational Drugs, vol. 10, no. 8, pp. 860-870, 2009.

[151] J. Arroyo, J. Hutzler, C. Bermejo et al., "Functional and genomic analyses of blocked protein O-mannosylation in baker's yeast," Molecular Microbiology, vol. 79, no. 6, pp. 1529-1546, 2011.

[152] C. A. McLellan, L. Whitesell, O. D. King, A. K. Lancaster, R. Mazitschek, and S. Lindquist, "Inhibiting GPI anchor biosynthesis in fungi stresses the endoplasmic reticulum and enhances immunogenicity," ACS Chemical Biology, vol. 7, no. 9, pp. 15201528, 2012.

[153] C. A. McLellan, L. Whitesell, O. D. King, A. K. Lancaster, R. Mazitschek, and S. Lindquist, "Correction to inhibiting GPI anchor biosynthesis in fungi stresses the endoplasmic reticulum and enhances immunogenicity," ACS Chemical Biology, vol. 9, no. 4, p. 1061, 2014.

[154] N. Watanabe, M. Miyazaki, T. Horii, K. Sagane, K. Tsukahara, and K. Hata, "E1210, a new broad-spectrum antifungal, suppresses Candida albicans hyphal growth through inhibition of glycosylphosphatidylinositol biosynthesis," Antimicrobial Agents and Chemotherapy, vol. 56, no. 2, pp. 960-971, 2012. 

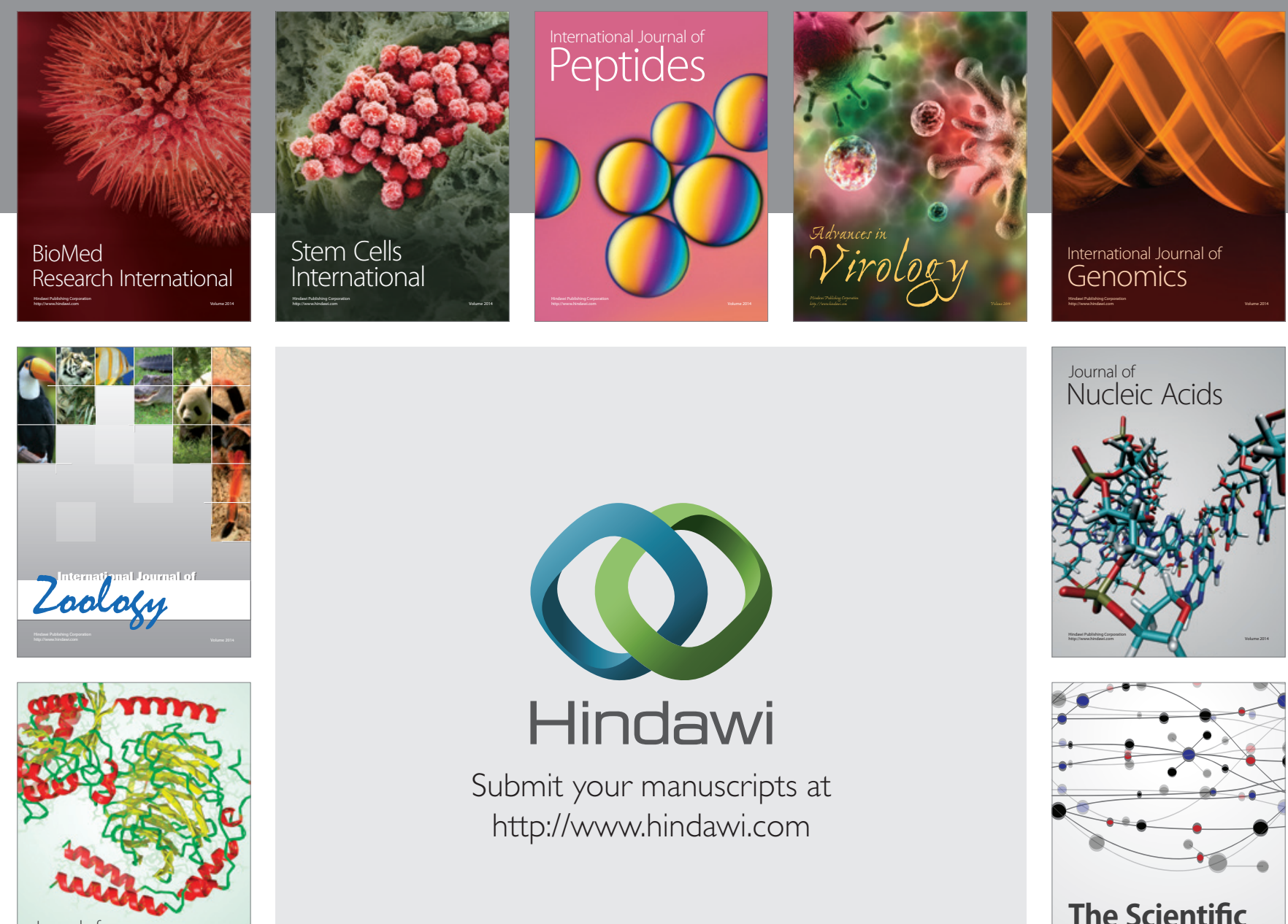

Submit your manuscripts at

http://www.hindawi.com

Journal of
Signal Transduction
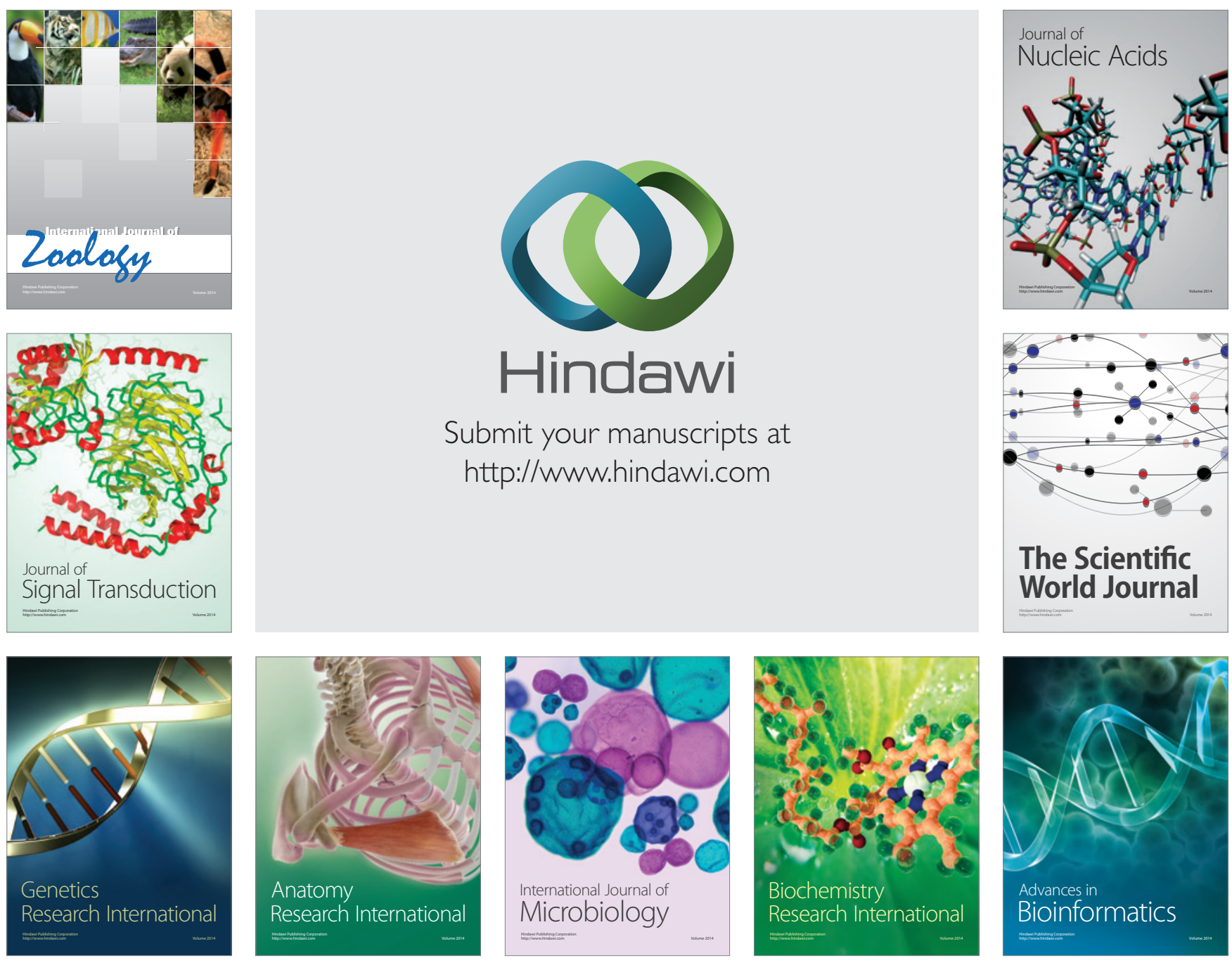

The Scientific World Journal
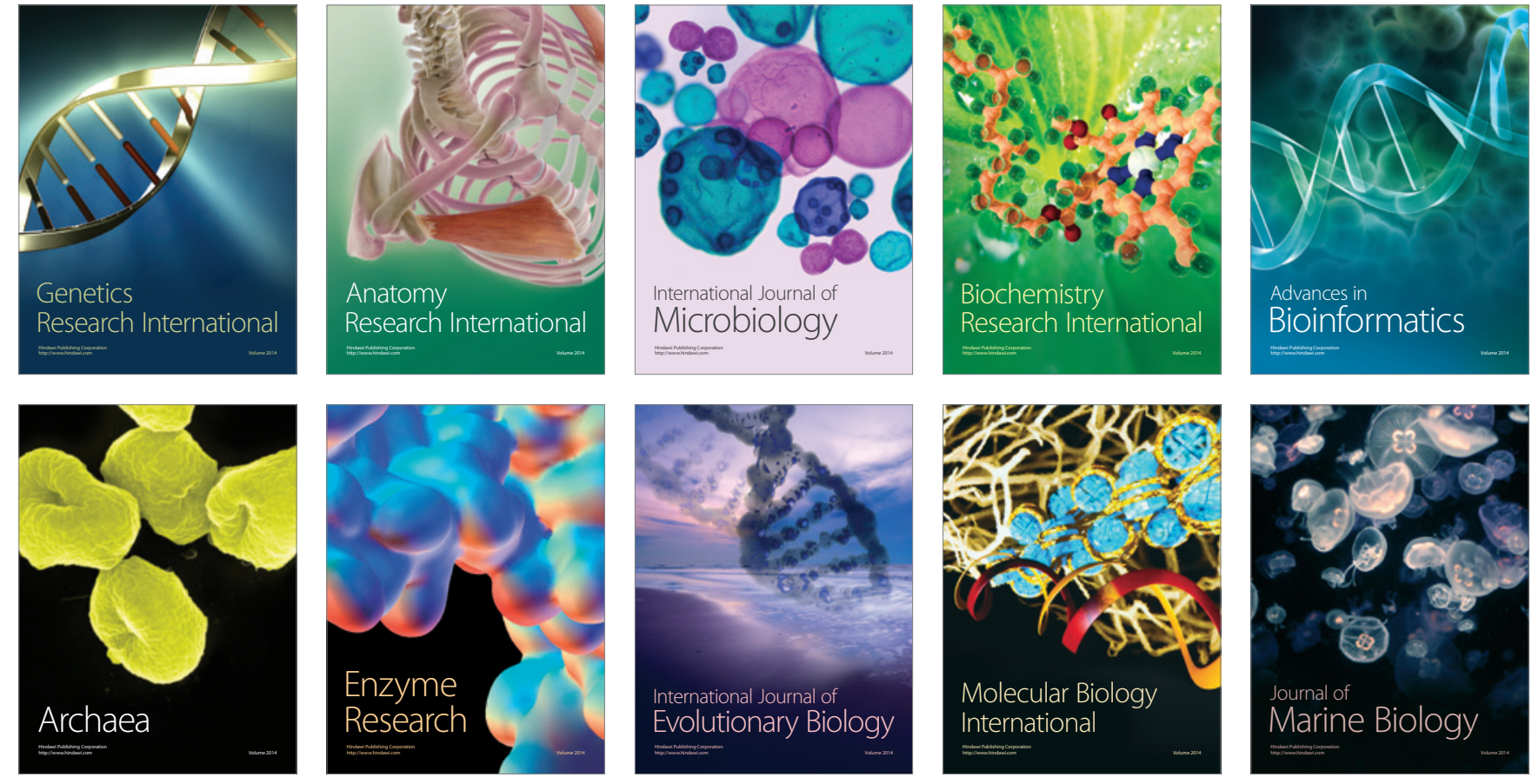